\title{
PLACING THE FLORIDIAN MARINE GENETIC DISJUNCTION INTO A REGIONAL EVOLUTIONARY CONTEXT USING THE SCORCHED MUSSEL, BRACHIDONTES EXUSTUS, SPECIES COMPLEX
}

\author{
TAEHWAN LeE ${ }^{1,2}$ AND Diarmaid Ó FoighiL ${ }^{1,3}$ \\ ${ }^{1}$ Museum of Zoology and Department of Ecology and Evolutionary Biology, University of Michigan, \\ Ann Arbor, Michigan 48109-1079 \\ ${ }^{2}$ E-mail: taehwanl@umich.edu \\ ${ }^{3}$ E-mail: diarmaid@umich.edu
}

\begin{abstract}
The well-documented Floridian Gulf/Atlantic marine genetic disjunction provides an influential example of presumed vicariant cladogenesis along a continental coastline for major elements of a diverse nearshore fauna. However, it is unclear if this disjunction represents a local anomaly for regionally distributed morphospecies, or if it is merely one of many such cryptic phylogenetic splits that underlay their assumed genetic cohesiveness. We aimed to place the previously characterized scorched mussel Gulf/Atlantic genetic disjunction into a regional phylogenetic perspective by incorporating genotypes of nominal conspecifics sampled throughout the Caribbean Basin as well as those of eastern Pacific potential geminate species. Our results show it to be one of multiple latent regional genetic disjunctions, involving five cryptic Caribbean species, that appear to be the product of a long history of regional cladogenesis. Disjunctions involving three stem lineages clearly predate formation of the Isthmus of Panama and of the Caribbean Sea, although four of the five cryptic species have within-basin sister relationships. Surprisingly, the Atlantic clade was also found to be widespread in the southern Caribbean, and ancestral demography calculations through time for Atlantic coast-specific genotypes are consistent with a northward range extension after the last glacial maximum. Our new data seriously undermine the hypothesis of a Floridian vicariant genesis and imply that the scorched mussel Gulf/Atlantic disjunction represents a case of geographic and temporal pseudocongruence. All five Caribbean Basin cryptic species exhibited an intriguing pattern of predominantly allopatric distribution characterized by distinct geographic areas of ecological dominance, often adjoining those of sister taxa. This pattern of distribution is consistent with allopatric speciation origins, coupled with restricted postspeciation range extensions. Several lines of indirect evidence favor the hypothesis that the predominantly allopatric distributions are maintained over evolutionary time scales, primarily by postrecruitment ecological filters rather than by oceanographic barriers to larvalmediated gene flow.
\end{abstract}

Key words._Bivalvia, Caribbean, cryptic species, genetic disjunction, phylogeny, pseudocongruence.

Received April 6, 2005. Accepted July 25, 2005.

Comparative molecular studies can yield important and novel insights into marine biodiversification processes by placing the genetic structuring of taxa into an inferred historical context (Grosberg and Cunningham 2001). Of particular interest are studies in which previously unsuspected genetic discontinuities, common to diverse faunal elements, have been uncovered (Lavery et al. 1996; Borsa et al. 1997; Chase et al. 1998; Gopurenko et al. 1999), and the most prominent such case concerns the marine fauna of peninsular Florida (reviewed by Avise 1992, 2000; Cunningham and Collins 1994, 1998; Palumbi 1994).

From a marine biogeographic perspective, peninsular Florida provides one of the most intriguing and best-studied nearshore evolutionary landscapes. The southern section of the Floridian landmass projects into tropical marine waters, thereby isolating disjunct warm temperate water bodies on its northeastern (Atlantic) and northwestern (Gulf of Mexico) flanks. Briggs $(1970,1974)$, on the basis of faunistic similarity, grouped both Atlantic and Gulf warm temperate faunas into the Carolinian zoogeographic province. Many, but by no means all, Carolinian morphospecies presently have a distinctly allopatric distribution along the Floridian coastline (Avise 1992, 2000; Cunningham and Collins 1994, 1998). Their last direct contact may have occurred during Pleistocene glacial maxima (Cronin 1988; Pielou 1991; Wares 2002) or earlier via the Miocene Suwannee Seaway, a former marine connection across the northern flank of the peninsula (Bert
1986; Bert and Harrison 1988; Webb 1990; Cunningham et al. 1991; Felder and Staton 1994; Randazzo and Jones 1997).

Replicate genetic characterizations of nominal species (including continuously distributed taxa) found on either flank of the Floridian peninsula have revealed cryptic phylogenetic disjunctions among diverse Gulf/Atlantic Carolinian marine faunal elements (Avise 2000). Although some of the studied taxa showed no obvious genetic structuring along the peninsular coastline (Gold and Richardson 1998; Avise 2000; Kirkendale et al. 2004), many yielded a Gulf/Atlantic genetic disjunction in which genetic divergence levels among the two disjunct populations far surpassed that observed within either population (Avise 2000). Such disjunct patterns have been detected in a wide variety of nearshore species (Bert 1986; Saunders et al. 1986; Avise et al. 1987; Bert and Harrison 1988; Cunningham et al. 1991; Sarver et al. 1992; Felder and Staton 1994; Bert and Arnold 1995; Duggins et al. 1995; Ó Foighil et al. 1996; Schizas et al. 1999; Avise 2000; Collin 2001, 2002), with by far the most intensively studied exemplar being the continuously distributed American oyster, Crassostrea virginica (Reeb and Avise 1990; Karl and Avise 1992; Hare and Avise 1996, 1998; Hare et al. 1996; McDonald et al. 1996).

The well-documented Gulf/Atlantic genetic disjunction is important because it has become the most influential example of how vicariance events may profoundly mold the genetic structuring of a diverse nearshore marine fauna in an osten- 
sibly continuous coastal environment (Avise 2000). However, the general applicability of the Gulf/Atlantic study system is limited because its findings have not been placed within a regional geographic and phylogenetic perspective. Does it represent a local anomaly that has no equivalent in and little phylogenetic relevance to other parts of the geographic range of regionally distributed morphospecies? Or might it represent but one of a nested series of cryptic phylogenetic splits that underlay their assumed genetic cohesiveness?

These are pertinent questions because a large fraction of the Carolinian fauna is not restricted to this particular zoogeographic province. In many cases, such as the scorched mussel, Brachidontes exustus, the nominal range of constituent morphospecies extends from the Atlantic coast of the southeastern United States, throughout the Gulf of Mexico and the Caribbean, and also includes Bermuda (Abbott 1974; Sterrer 1986). This expansive regional range encompasses a much more complex evolutionary landscape in which the Suwannee Seaway closure represents but one local element of a dynamic geological history that has profoundly reconfigured continental, oceanic, and archipelagean interfaces (Droxler et al. 1998; Iturralde-Vinent and MacPhee 1999).

Until recently, the prevailing paradigm for Caribbean marine taxa was that they typically exhibited extensive withinBasin distributions in association with little apparent genetic structuring (Mitton et al. 1989; Lacson 1992; Hateley and Sleeter 1993; Shulman and Bermingham 1995; Lessios et al. 2001, 2003; Rocha et al. 2002; Williams and Reid 2004). However, more recent reef fish studies have begun to challenge this consensus by uncovering latent genetic structuring, despite extended pelagic larval development, that either has a clear allopatric signature, as in the cleaner goby, Elacatinus (Taylor and Hellberg 2003a), or else is consistent with parapatric ecological speciation, as in Halichoeres wrasses (Rocha et al. 2005). The Elacatinus data has been the subject of contrasting genes versus oceanography interpretations, with the former proposing that the geographic partitioning of discrete lineages is maintained by genetically mediated aspects of this species' larval or postlarval ecology (Taylor and Hellberg 2003b; Warner and Palumbi 2003), and the latter emphasizing the role of oceanographic features in promoting passive local larval retention (Colin 2003).

Brachidontes mussels date at least from the Jurassic (Coan et al. 2000) and are common constituents of regional intertidal faunas, typically attaching to hard substrates using byssal threads (Abbott 1974; Sterrer 1986). They have a planktotrophic larval mode of development, which may persist for up to 40 days in laboratory conditions (Campos and Ramorino 1980; Fields and Moore 1983). We have recently characterized the genetic structure of Floridian B. exustus populations using mitochondrial and nuclear markers (Lee and Ó Foighil 2004). Both sets of markers recovered the expected disjunction involving sister clades distributed on alternate flanks of peninsular Florida and lineage-specific mitochondrial molecular clocks placed its origin in the Pliocene. Our primary novel result, however, was the discovery that the Gulf/Atlantic disjunction represents but one of three cryptic, nested genetic discontinuities represented in Floridian scorched mussel populations. The most pronounced phylogenetic split distinguished the Gulf and Atlantic sister clades from two additional cryptic sister clades present in samples taken from the southern Florida tropical marine zone. Floridian populations of $B$. exustus were composed of four cryptic taxa, a result consistent with the hypothesis that the Gulf/Atlantic disjunction in this morphospecies is but one of multiple latent regional genetic breakpoints.

The goal of this present study was to place the Gulf/Atlantic scorched mussel genetic disjunction into a regional phylogenetic perspective by incorporating genotypes of nominal conspecifics sampled throughout the Caribbean Basin as well as those of eastern Pacific potential geminate species. Our results indicated that this regional morphospecies is composed of three stem lineages that predate closure of the Isthmus of Panama and incorporates five cryptic Caribbean species that display largely allopatric within-basin distributions. The Atlantic clade was found to be widespread in the southern Caribbean, and the Atlantic coast population appears to have resulted from a northward range extension after the last glacial maximum. The scorched mussel Gulf/Atlantic disjunction appears to represent a case of geographic and temporal pseudocongruence (Cunningham and Collins 1994) and may not be a product of Floridian vicariance.

\section{Materials And Methods}

\section{Samples}

Nominal specimens of B. exustus were sampled from 22 localities throughout the Caribbean Basin (Table 1). It is now clear that $B$. exustus is a cryptic species complex (Lee and Ó Foighil 2004) and, whenever possible, at least 15 individuals per locality were genotyped to ensure that the primary local genotypes were sampled. Additional Brachidontes species were collected, including $B$. modiolus, a morphologically distinct Caribbean congener; two Panamian eastern Pacific species, $B$. adamsianus and $B$. semilaevis; and a variety of other global congeners. We used regional Geukensia and Ischadium taxa as outgroups in addition to representatives of four other mytilid genera (Lithophaga, Modiolus, Mytilus, and Septifer). A summary of the sampling locations and of voucher specimen information is outlined in Table 1. Detailed sampling records have been deposited together with the voucher specimens in the Mollusk Collection of the University of Michigan's Museum of Zoology. Specimens were preserved in $95 \%$ ethanol prior to molecular characterization.

\section{Molecular Data}

Total genomic DNA was isolated from the posterior adductor muscle to avoid male gonadal tissue enriched with paternally transmitted "male" mitochondrial genomes prevalent in Mytilidae (Rawson and Hilbish 1995; Quesada et al. 1996; Lee and Ó Foighil 2004). We are confident that this measure was successful due to the lack of heteroplasmy observed in our direct sequences and to the topological congruence among our mitochondrial and nuclear markers (Lee and Ó Foighil 2004). The extraction was done using a DNeasy Tissue Kit (Qiagen, Valencia, CA) according to the manufacturer's instructions. Three target fragments were amplified and directly sequenced: mitochondrial cytochrome $c$ oxidase subunit I (COI), nuclear ribosomal large subunit (28S), and 
TABLE 1. Samples collected for this study with voucher specimen information (University of Michigan Museum of Zoology catalog number).

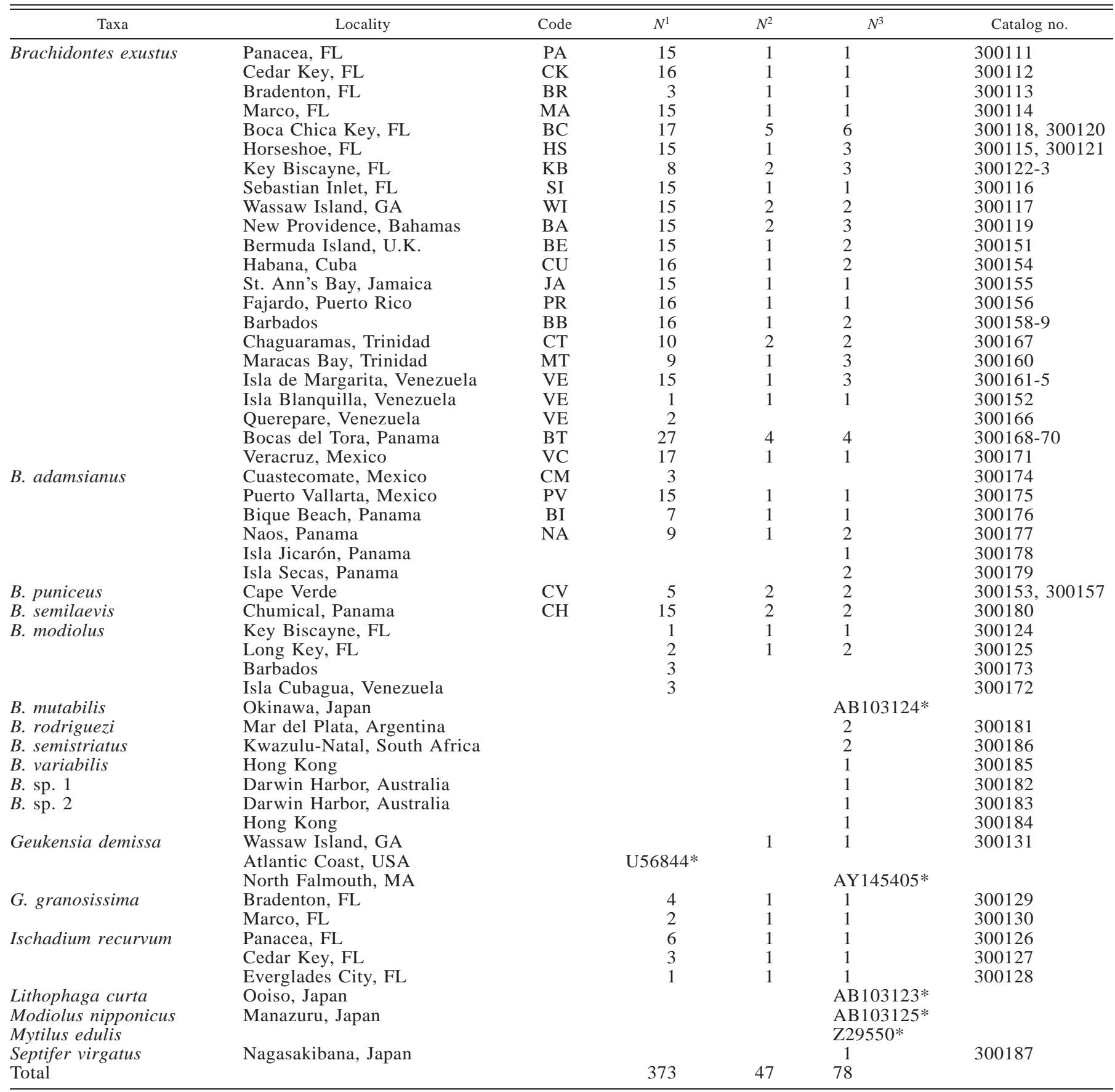

* Sequence obtained from GenBank.

${ }^{1} N$ : number of individuals typed for COI.

${ }^{2} N$ : number of individuals typed for ITS 1.

${ }^{3} N$ : number of individuals typed for $28 \mathrm{~S}$.

nuclear ribosomal first internal spacer (ITS1). Polymerase chain reactions (PCRs) were performed to amplify a 660 nucleotide (nt) portion of COI, $771 \mathrm{nt}$ (aligned length) of $28 \mathrm{~S}$, and $637 \mathrm{nt}$ (aligned length) of ITS1 using primer pair LCO1490/HCO2198 (Folmer et al. 1994), D23F/D6R (Park and Ó Foighil 2000), and primers annealing to flanking regions of the $18 \mathrm{~S}$ and $5.8 \mathrm{~S}$ genes (White et al. 1996), re- spectively. The target fragments were amplified with GoTaq DNA Polymerase (Promega, Madison, WI) and a negative control (no template) was included in each amplification run. For all reactions, a touchdown protocol (Palumbi 1996) was utilized. After 2 min denatuation at $95^{\circ} \mathrm{C}$, an initial annealing temperature of $65^{\circ} \mathrm{C}$ was decreased by $2^{\circ} \mathrm{C}$ per cycle $(30 \mathrm{sec}$ denaturing at $95^{\circ} \mathrm{C}, 40 \mathrm{sec}$ annealing, and $1 \mathrm{~min}$ extension 
at $72^{\circ} \mathrm{C}$ ) until the final gene-specific annealing temperature $\left(45^{\circ} \mathrm{C}\right.$ for COI and $52^{\circ} \mathrm{C}$ for $28 \mathrm{~S}$ and ITS 1 ) was reached and subsequently maintained for an additional 30 cycles. Doublestranded products were isolated on $1 \%$ agarose gels, excised over UV light, and extracted using a QIAquick gel extraction kit (Qiagen). Both strands of the amplified fragments were directly cycle-sequenced, using the PCR primers, by the University of Michigan's Sequencing Core Facility. All novel DNA sequences have been deposited in GenBank (COI: AY825105-AY825222, 28S: AY825079-AY825104, ITS1: AY825223-AY625245). Previously generated sequences (AY621835-AY622009, Lee and Ó Foighil 2004) representing Floridian genetic variation were also included and a few sequences, mainly for outgoup taxa, were retrieved from the GenBank database (see Table 1).

\section{Phylogenetic Analyses}

Sequence chromatograms were edited by comparing both strands for all taxa using Sequence Navigator 1.0.1 (Applied Biosystems, Foster City, CA). COI sequences were aligned easily due to an absence of indels. The nuclear ribosomal DNA fragments were aligned with Clustal X (Thompson et al. 1997) using default parameters and then adjusted manually where necessary. A partition-homogeneity test (Farris et al. 1995) was performed (100 random replications) using PAUP*4.0b10 (Swofford 2003) to evaluate character congruence among $28 \mathrm{~S}$ and ITS1 datasets.

Phylogenetic relationships among Caribbean and putative geminate Brachidontes taxa were analyzed with COI and combined nuclear rDNA (28S + ITS1) datasets using Floridian Geukensia and Ischadium species as outgroups (Distel 2000). In addition, a global Brachidontes phylogeny was constructed from 28S dataset using four mytilid genera (Mytilus, Modiolus, Lithophaga, and Septifer) as outgroups. Maximum parsimony (MP) analyses were conducted with PAUP* using heuristic search option (100 random stepwise additions and tree bisection-reconnection branch-swapping). Nodal support was estimated through bootstrap analysis (Felsenstein 1985) using 100 replications with 10 random additions per each bootstrap replicate. Because of the extensive computational time, the maximum number of trees to be saved was limited to 5000 and bootstrap values were accessed with the fast stepwise-addition option for heuristic searches $(10,000$ replicates) when the COI dataset was analyzed.

Bayesian analysis was also performed on each dataset using MrBayes 3.0b4 (Ronquist and Huelsenbeck 2003) under the best-fit substitution model (GTR $+\mathrm{I}+\Gamma$ for COI and $28 \mathrm{~S}$ datasets and GTR + I for $28 \mathrm{~S}$ and ITS 1 combined dataset) determined by hierarchical likelihood ratio tests (hLRTs) as implemented in Modeltest 3.06 (Posada and Crandall 1998). Model parameters were treated as unknown and were estimated for each analysis. The COI third-codon position was set up to have different gamma-distributed rate variation $(\Gamma)$ and proportion of invariant sites (I) than the first and second position in the analysis of COI dataset. Random starting trees were used and analyses were run for 1 million generations, sampling every 100 generations for each dataset. Posterior probability values were estimated by gen- erating a $50 \%$ majority rule consensus tree after the burn-in period of 2000 using PAUP*.

\section{Within-Clade Genetic Structure and Migration Rates}

Genetic structures of major nominal B. exustus COI clades recovered were characterized using Arlequin 2.001 (Schneider et al. 2000). Genetic variation within each clade was estimated using haplotype diversity ( $H$; Nei 1987) and nucleotide diversity $(\pi$, the mean of pairwise sequence differences; Tajima 1983). Tajima's (1989) $D$-statistic (10,000 permutations) was computed to test for selective neutrality of mitochondrial COI sequences. The fraction of the total genetic variation distributed among populations was estimated with the analysis of molecular variation (AMOVA; Excoffier et al. 1992) based on simple pairwise distance. Populations represented by a single mussel, in addition to the Cape Verde population (which is geographically isolated and phylogenetically divergent from its sister populations), were removed from the analyses to avoid biased estimates. A parsimony network was constructed for each clade using the statistical parsimony (Templeton et al. 1992) method in TCS 1.13 (Clement et al. 2000).

We estimated patterns of gene flow among populations within each of the major nominal B. exustus COI clades using Migrate 1.7.6 (Beerli and Felsenstein 2001), which estimates directional and asymmetric gene flow using a Markov chain Monte Carlo maximum-likelihood procedure. Populations with small sample sizes $(\leq 5)$ were not included in this analysis. A maximum-likelihood (ML) corrected transition to transversion ratio of 6.732, calculated from the Bayesian tree using PAUP*, and empirical base frequencies were used. Each search run involved 10 short chains with 100,000 sampled genealogies and three long chains with 1 million sampled genealogies. For both the short and long chains, 10,000 genealogies were discarded as initial burn-in. A static heating scheme, four chains with temperatures 1.0, 1.2, 1.5, and 3.0, was used. Three initial searches were conducted for each clade with different random seeds and $F_{\mathrm{ST}}$-based estimates of $\Theta(=2 N \mu$ for the mtDNA genome, where $N$ is the effective population size and $\mu$ is the mutation rate) and migration rates $(M=2 m N$, where $m$ is migration rate per generation in a population) to check consistency of the results. Three additional runs were performed with parameter estimates from the previous run as starting values.

\section{Estimation of Sequence Divergence Rates and Divergence Times}

We estimated Brachidontes specific mitochondrial COI mutation rates by calibrating rates of third-codon position sequence divergence among two putative transisthmian geminates identified by phylogenetic analyses of mitochondrial COI and combined nuclear rDNA datasets. Prior to rate calculation, evidence of substitution saturation was investigated by plotting the pairwise third-codon position differences (uncorrected) against GTR $+\mathrm{I}+\Gamma$-corrected pairwise distances for all codon positions (Fig. 1). Third positions saturated rapidly, suggesting that saturation started to occur slightly prior to the divergence of geminate 2 and that by the time when geminate 1 diverged third positions appeared to be 


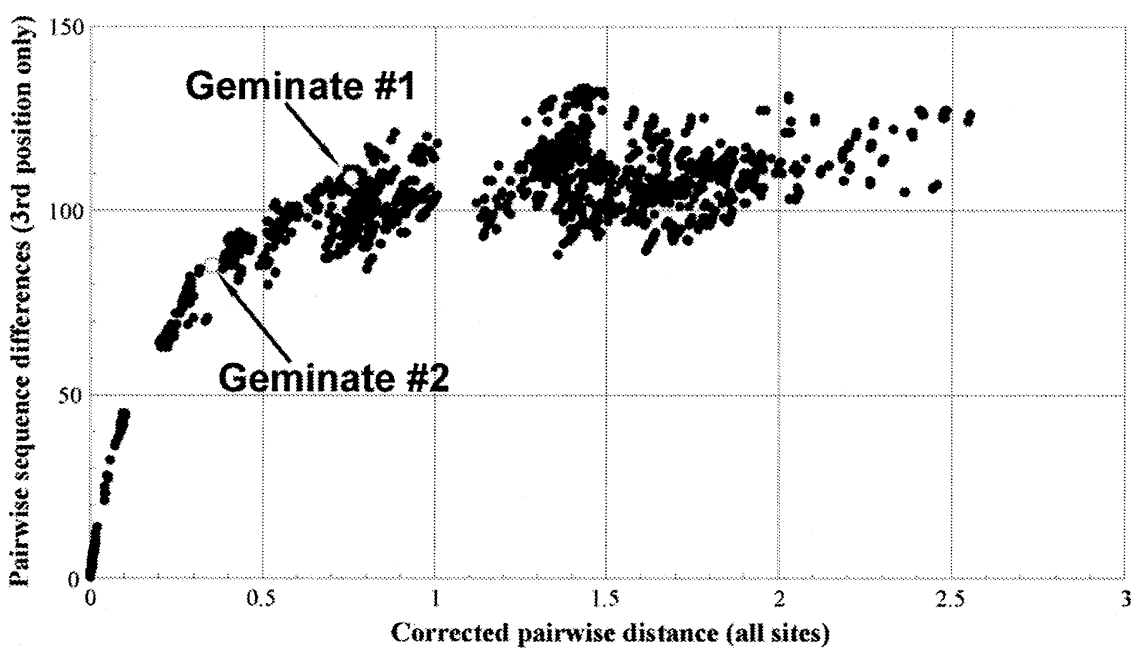

FIG. 1. Plots of third-codon position substitution saturation for the mitochondrial COI dataset, including outgroup taxa. The uncorrected pairwise sequence differences for third codon positions ( $\mathrm{y}$-axis) are plotted against GTR $+\mathrm{I}+\Gamma$-corrected pairwise distances for all codon positions (x-axis). Plots for two putative geminate pairs (unfilled circles) are based on average pairwise distances.

completely saturated. To test the rate consistency of a Poisson-distributed molecular clock, likelihood ratio tests (Felsenstein 1981) were conducted using the HKY substitution model, which was chosen by hLRTs using Modeltest, and a molecular clock could not be rejected for COI third-codon positions $(\delta=58.035$, df $=56, P>0.10)$. In these analyses, the COI data matrix was pruned to 58 haplotypes representing all of the clades recovered in the analysis of the total COI dataset, including outgroups, to minimize computational time requirements.

In a calculation of third-position divergence rates, net nucleotide divergences ( $d$, Nei and Li 1979) among two geminate pairs were calculated based on HKY corrected pairwise sequence divergences using all COI haplotypes to account for ancestral within-lineage variation (Edward and Beerli 2000). These estimates were then calibrated at two dates: 3.6 million years (Coates et al. 1992) and at 2.7 million years (Marshall 1988). These calibration dates are likely to span the actual cessation of gene flow for intertidal Brachidontes because the former is based on the differentiation of nearshore molluscan paleofaunas and the latter on the intercontinental exchange of land mammals. COI third positions diverged at rates of $51.93-69.24 \%$ and $36.58-48.77 \%$ per million years based on geminate 1 and 2 calibrations, respectively, yielding estimates of $25.96-34.62 \%$ and 18.29 $24.38 \%$ per million years per lineage. The mutation rates calibrated by geminate $2(18.29-24.38 \%$ per million years per lineage) were further used to estimate divergence times among $B$. exustus clades because the best estimate is likely from the least divergent geminate clade (Knowlton and Weight 1998; Lessios et al. 2001) and it exhibits less saturation (Fig. 1). Divergence times were determined by calculating net third-position divergences among B. exustus major COI clades.

\section{Estimation of Ancestral Population Parameters}

COI haplotypes of the B. exustus Atlantic clade were divided into two datasets, one with all haplotypes and the other with unambiguous northern haplotypes only (see Results). Ancestral population parameters, $\Theta(=2 N \mu$ for the mtDNA genome, where $N$ is the effective population size and $\mu$ is the mutation rate) and $g$ (the exponential growth rate of the population) were jointly calculated for the each dataset using COI third-codon positions only with Fluctuate 1.4 (Kuhner et al. 1998). Analyses were repeated 10 times for each dataset using 10 short chains of 5000 steps each and five long chains of 25,000, with sampling increments of 20, and the mean values were calculated. Each analysis used a ML-corrected transition-to-transversion ratio, estimated using PAUP* under the HKY substitution model. COI third-position divergence rates obtained above were converted into mutation rates per generation, assuming a Brachidontes generation time of 3 years (Morton 1988). These estimates were used to generate the relative effective population size at any time $t$ with the equation $N_{t}=\Theta^{\mathrm{e}-\left(g_{\mu}\right) t}$ (Kuhner et al. 1998).

\section{RESULTS}

\section{Phylogenetic Analyses}

A Brachidontes phylogeny constructed from the nuclear $28 \mathrm{~S}$ dataset is shown in Figure 2. It incorporates 78 genotypes generated from nine nominal and two unidentified Brachidontes species, in addition to outgroups (Table 1). Both MP and Bayesian analyses recovered a well-supported Brachidontes clade sister to GeukensialIschadium taxa. Nominal B. exustus genotypes were not monophyletic, being present in three distinct tip clades, each of which also contained a nonCaribbean congener: eastern Pacific B. semilaevis, one of two polyphyletic eastern Pacific $B$. adamsianus lineages, and eastern Atlantic B. puniceus. The Caribbean congener, B. modiolus, which shares much of its distribution with nominal B. exustus, was not included in this species complex. Instead, $B$. modiolus grouped with diverse congeners from the eastern Pacific (B. adamsianus second polyphyletic lineage), western South Atlantic (B. rodriguezi) and a variety of western Pacific lineages (B. mutabilis, B. sp. 1, and B. sp. 2) in the Bayesian 


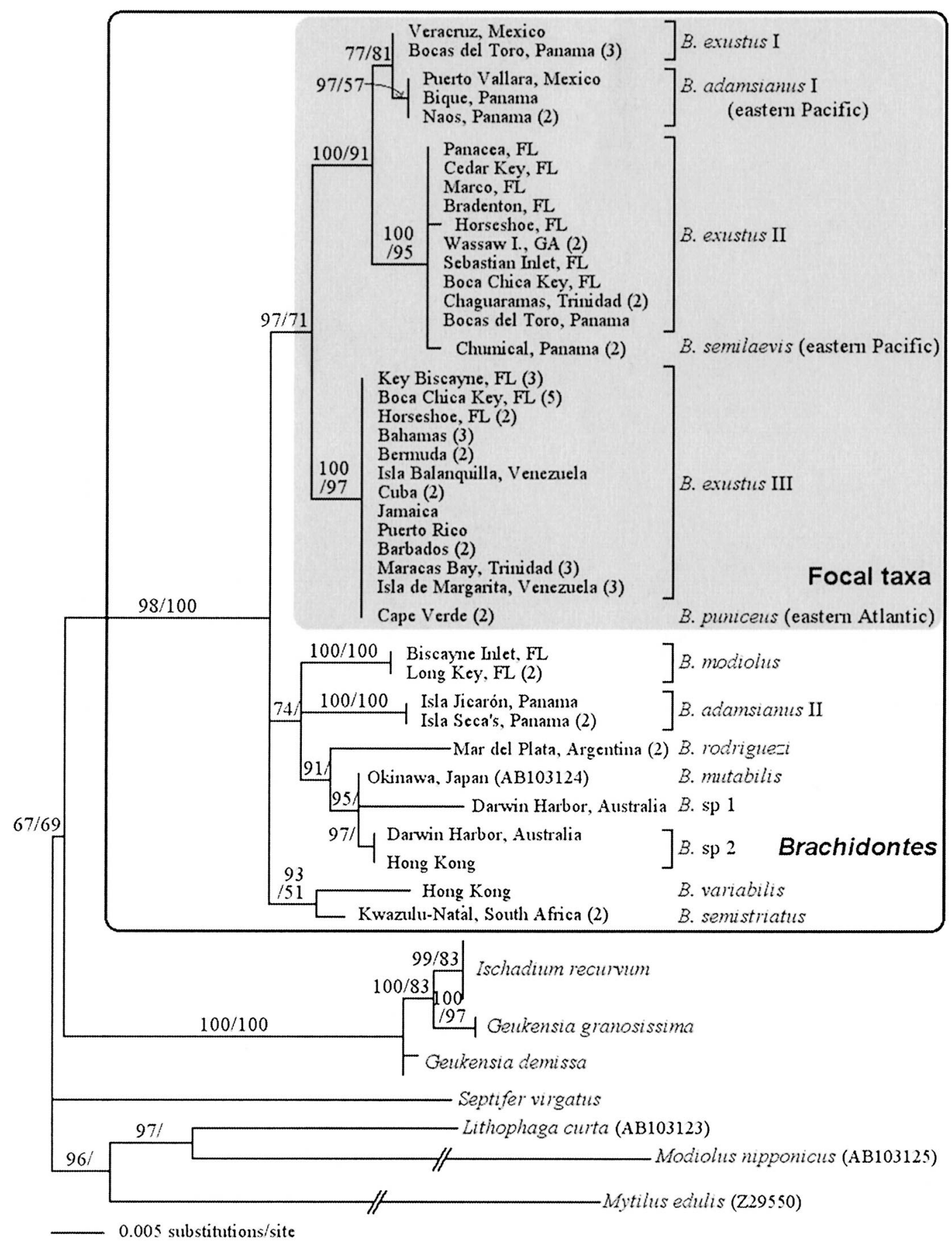

FIG. 2. Bayesian tree for globally collected Brachidontes taxa based on nuclear 28S sequence data using representatives of four mytilid genera (Lithophaga, Modiolus, Mytilus, and Septifer) as outgroups. Nodal support values (Bayesian posterior probability/parsimony bootstrap) are indicated above the branches. Numbers in parentheses following sampling locations indicate multiple individuals sharing the same genotype.

analysis. The polyphyletic status of $B$. exustus has already been established (Lee and Ó Foighil 2004), and Figure 2 demonstrates that cryptic species complexes are also prevalent in other global populations of Brachidontes, including those in the eastern Pacific (Panama), Hong Kong, and Northern Australia (Darwin). The taxonomic details of these complexes remain to be determined, however, the global gene tree (Fig. 2) shows that the B. exustus cryptic species complex is part of a phylogenetically distinctive and, according to available data, almost exclusively Neotropical lineage.

An extensive mitochondrial COI database was constructed for the focal taxa (Fig. 2) and cross-referenced using nuclear ribosomal markers. The mitochondrial database consisted of 150 nominal B. exustus COI haplotypes (representing 293 
individuals, Table 2) obtained by combining a previous Florida/Bahamas dataset (Lee and Ó Foighil 2004) with 69 new genotypes sampled from 12 Caribbean/Bermudan localities (Table 1). Multiple individuals of the three non-Caribbean sister species recovered in $28 \mathrm{~S}$ gene tree (B. adamsianus [the sister polyphyletic lineage only], B. semilaevis, and B. puniceus), and of the coexisting congener B. modiolus, were also characterized for COI. A subsample of 32 nominal B. exustus individuals representing the primary COI tree topological features and the main sampling locations were further genotyped for two nuclear ribosomal fragments (28S and ITS1; Table $1)$. The two nuclear datasets were not significantly incongruent $(P=0.58$ in the partition-homogeneity test) and were analyzed as a combined dataset.

Bayesian and MP analyses were conducted on both combined nuclear and mitochondrial datasets using Geukensia and Ischadium species as outgroups (Fig. 3). These analyses recovered the same three stem 28S lineages (Fig. 2), albeit with much more tip resolution (especially so for the mitochondrial topologies), to reveal seven well-supported nuclear/mitochondrial terminal clades encompassing five nominal $B$. exustus lineages and three non-Caribbean nominal congeners. A novel western Caribbean lineage formed a robust clade with the eastern Pacific B. adamsianus (cryptic species I; Fig. 2) in both mitochondrial and nuclear analyses and these taxa putatively represent a transisthmian geminate species pair (Fig. 3, geminate 1). The other four nominal $B$. exustus clades were previously encountered in Floridian Brachidontes samples (Lee and Ó Foighil 2004) and clustered in two discrete tip clades (Fig. 3). As in the earlier study, the Gulf and Atlantic lineages were robustly sister to each other; however, B. semilaevis could now be identified as their putative transisthmian geminate (Fig. 3, geminate 2). The remaining Bahamas and Antilles (i.e., Key Biscayne clade of Lee and Ó Foighil, 2004) nominal B. exustus sister clades lacked putative geminates but the former surprisingly incorporated Cape Verde B. puniceus nominal congeners, most clearly for the nuclear rDNA markers (Fig. 3, indicated by asterisks).

Not all features of the nuclear and mitochondrial gene tree topologies (Fig. 3) were congruent. The primary discrepancy concerned the placement of $B$. modiolus. While it was robustly sister to the focal Brachidontes taxa in nuclear trees (Figs. 2, 3), B. modiolus formed weakly supported derived mitochondrial COI clades together with B. exustus Bahamas and Antilles clades: (B. modiolus (Bahamas, Antilles)) in the Bayesian tree (Fig. 3) and (Antilles (Bahamas, B. modiolus) in the MP strict consensus (not shown). Support values for the nominal B. exustus Bahamas/Antilles mitochondrial COI clade were much higher (Bayesian posterior probability of 100 and MP bootstrap of 80 ), when COI haplotypes of $B$. modiolus were excluded from the analyses.

\section{Caribbean Basin Phylogeography of Nominal Brachidontes} exustus Clades

\section{Western Caribbean clade}

As the informal name implies, this discrete lineage was restricted to western Caribbean continental samples, being encountered in large numbers at one site each in Mexico and

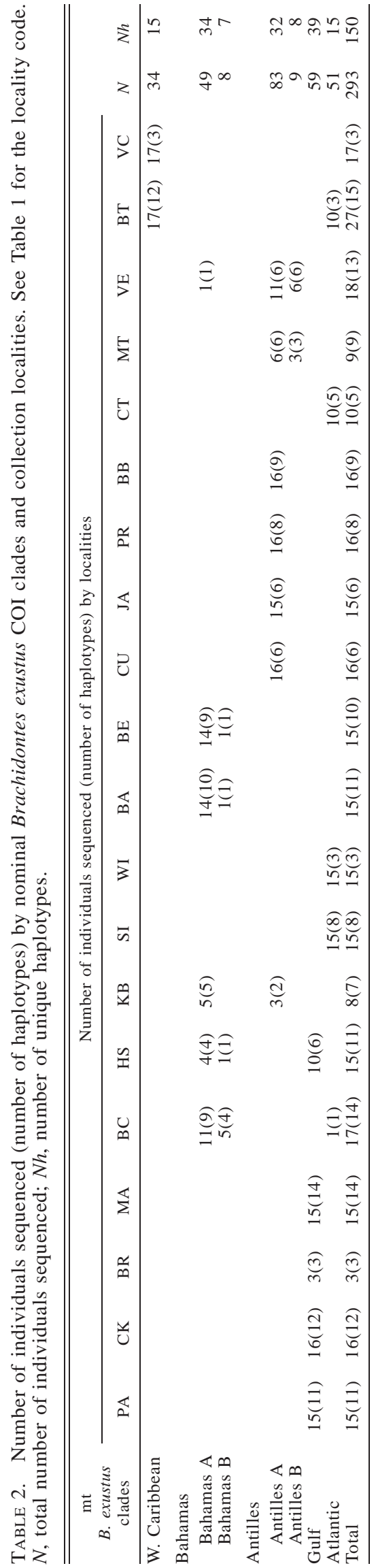




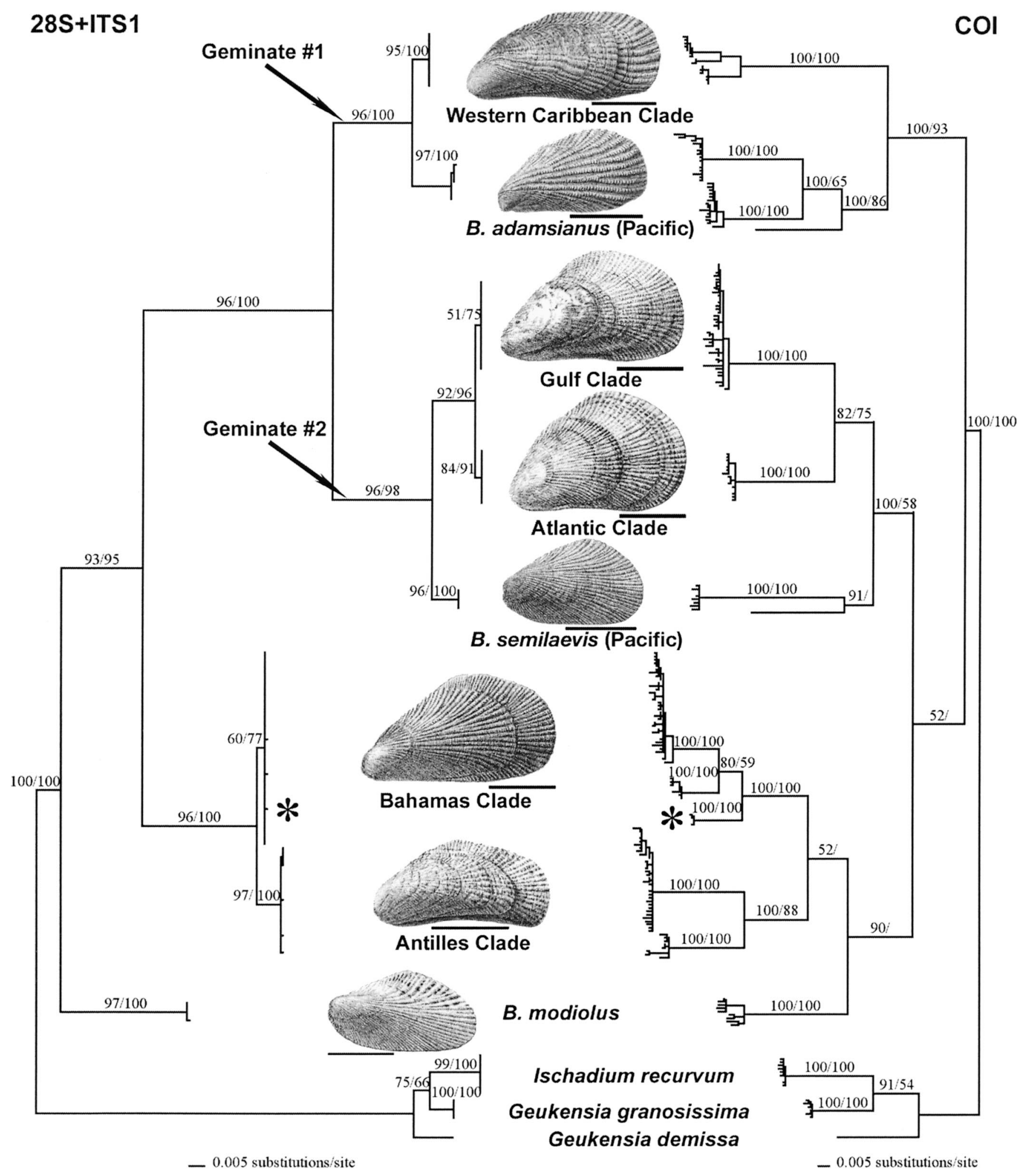

FIG. 3. Bayesian trees for focal Brachidontes taxa (see Fig. 2; the Caribbean B. modiolus, which shares much of its distribution with nominal B. exustus was also included) based on combined (28S and ITS1) nuclear ribosomal (left) and mitochondrial COI (right) datasets using Ischadium and Geukensia spp. as outgroup taxa. Numbers above the branches represent the Bayesian posterior probabilities/parsimony bootstrap values ( $>50$ only) for the supported nodes. Exemplar Brachidontes shell phenotypes are inserted, and scale bars represent 5 $\mathrm{mm}$. Genotypes for B. puniceus from Cape Verde are marked by asterisks, and inferred transisthmian geminate pairs are indicated by arrows. 


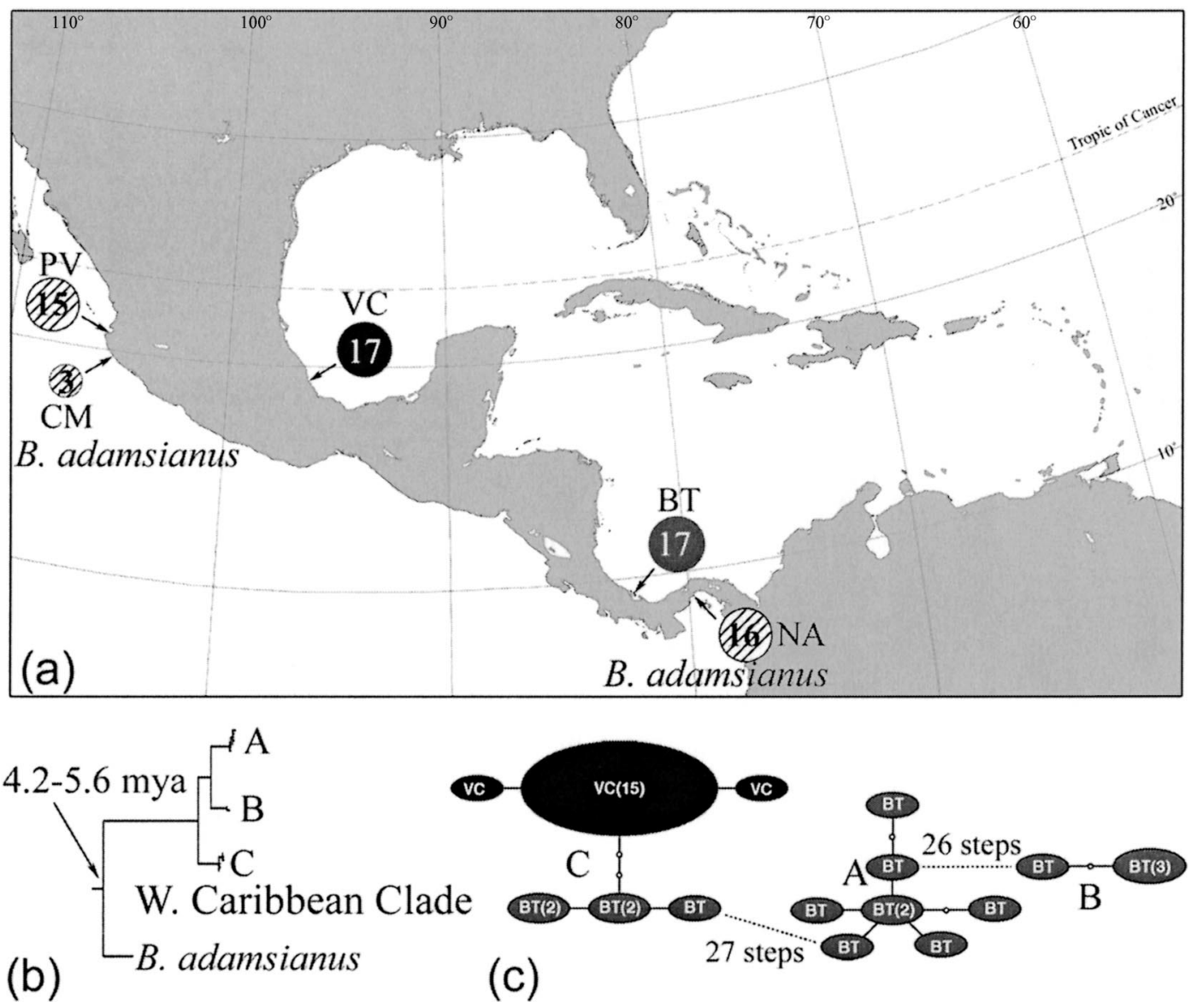

FIG. 4. Brachidontes exustus western Caribbean clade. (a) Map showing sampling locations (see Table 1 for locality code); (b) portion of COI Bayesian tree showing sister group relationships and inferred transisthmian divergence times; and (c) statistical parsimony network of western Caribbean COI genotypes. Three western Caribbean COI tip clades are labeled in capital letters in the Bayesian tree (b) and in the parsimony network (c). In the parsimony network, the observed COI haplotypes are represented by ovals sized according to their relative abundance (numbers $>1$ given in parentheses) and labeled and color-coded to reflect sampling location. Smaller unlabeled circles represent inferred missing haplotypes. Branch lengths connecting tip clades are from a minimum spanning tree computed using Arlequin 2.001 (Schneider et al. 2000).

Panama (Fig. 4a). Its sister taxon, the putatively geminate $B$. adamsianus, occurred in the eastern Pacific and contained three well-defined mitochondrial tip clades (Fig. 3). Our mitochondrial COI calibrations dated this transisthmian split at 4.2-5.6 million years ago (Fig. 4b), and this represents a minimal estimation calculated using the basal B. adamsianus tip clade (Fig. 3) that showed the smallest net divergence

TABle 3. Haplotype $(H)$ and nucleotide diversity $(\pi)$ with sampling variance and estimates of Tajima's $D$-statistic with associated level of significance $(* P<0.05)$ calculated for the major mitochondrial COI nominal Brachidontes exustus clades recovered.

\begin{tabular}{lccc}
\hline \hline $\begin{array}{c}\text { COI } \\
\begin{array}{c}\text { exustus } \\
\text { clades }\end{array}\end{array}$ & $\begin{array}{c}\text { Haplotype } \\
\text { diversity }(H)\end{array}$ & $\begin{array}{c}\text { Mean number of } \\
\text { pairwise } \\
\text { differences }(\pi)\end{array}$ & Tajima's $D$ \\
\hline $\begin{array}{c}\text { Western Carib- } \\
\text { bean clade }\end{array}$ & $0.802 \pm 0.069$ & $16.529 \pm 7.546$ & 1.1888 \\
Bahamas clade & $0.987 \pm 0.006$ & $20.380 \pm 9.126$ & -0.395 \\
Antilles clade & $0.890 \pm 0.025$ & $15.623 \pm 7.037$ & -0.805 \\
Gulf clade & $0.963 \pm 0.015$ & $5.425 \pm 2.651$ & $-1.809 *$ \\
Atlantic clade & $0.761 \pm 0.047$ & $2.954 \pm 1.572$ & -0.679 \\
\hline
\end{tabular}

from the western Caribbean sister taxon. Although the western Caribbean clade did not exhibit nuclear marker polymorphism (Fig. 3), its COI genotypes formed three distinct subclades, each of which was composed of a few haplotypes (Figs. 4b, c). This profile was reflected in low haplotype diversity but relatively high nucleotide diversity (Table 3). Northern and southern samples lacked common haplotypes (Fig. 4c), exhibited significant among-population genetic subdivision (Table 4), and showed no evidence of significant interpopulational gene flow (Table 5). The much lower levels of mitochondrial diversity in the northern sample (three haplotypes [one predominant] in the subclade $\mathrm{C}$ ), relative to that of the southern sample (12 haplotypes [none predominant] in all three subclades), appeared to be consistent with founder effect expectations.

\section{Bahamas and Antilles clades}

These two sister clades (Figs. 2, 3) were previously encountered in the earlier Floridian study, although at very different frequencies (Lee and Ó Foighil 2004). The expanded 
TABLE 4. Analysis of molecular variation results for major COI nominal Brachidontes exustus clades recovered.

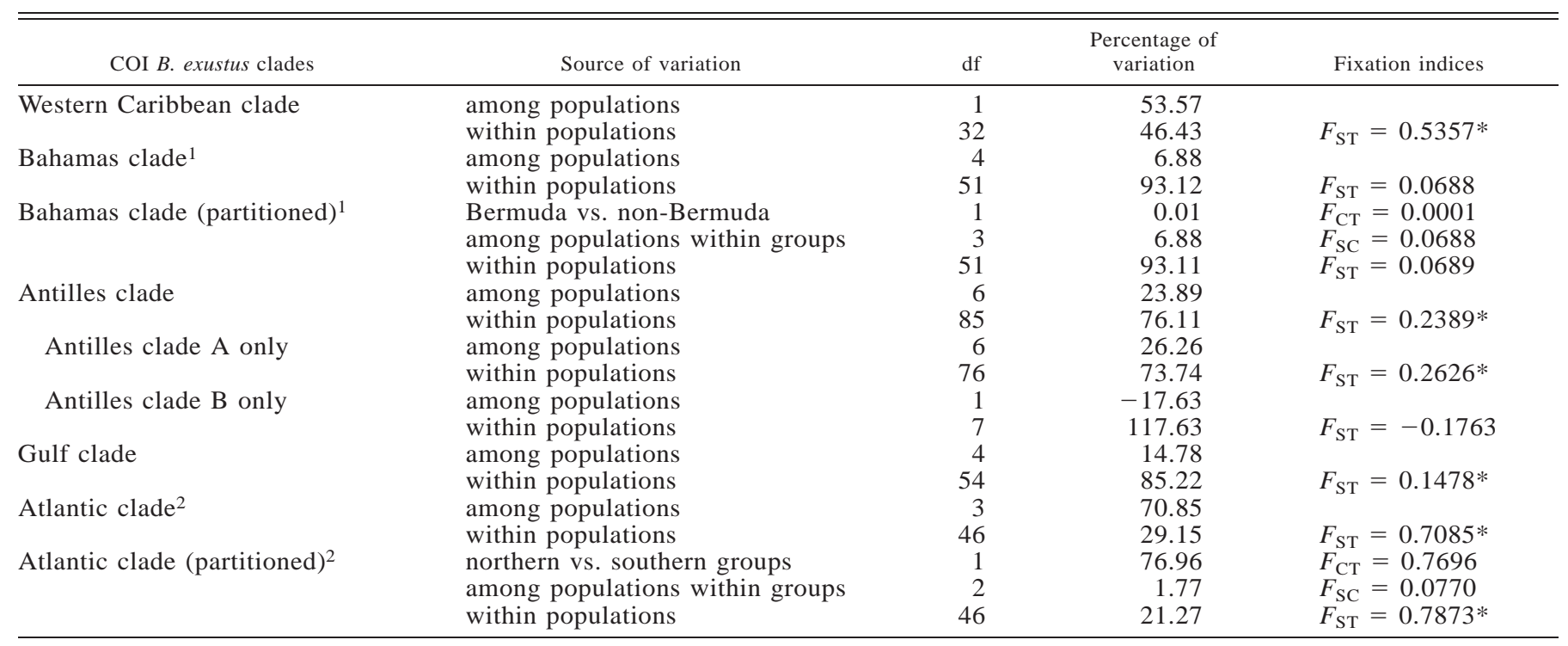

$* P<0.05$.

${ }^{1}$ A single mussel from Venezuela and five haplotypes from Cape Verde were removed from the analyses.

${ }^{2}$ A single individual sample from Boca Chica Key, FL, was removed from the analyses.

sampling of Caribbean populations revealed a striking pattern of predominantly allopatric north/south within-basin distributions and our mitochondrial COI calibrations dated this sister taxon split at 3.4-4.6 million years ago (Figs. 5a,b).

The Bahamas clade predominated in the Florida Keys, Bahamas, and Bermuda sampling sites, being exclusively present in the latter two samples. Surprisingly, this clade also had an amphi-Atlantic distribution and incorporated the nominal Cape Verdean congener B. puniceus, unambiguously so for the nuclear markers (Figs. 2, 3) and as a well-supported tip sister clade for the mitochondrial marker (Figs. 3, 5c). It is also noteworthy that a single Bahamas clade specimen (confirmed with both mitochondrial and nuclear markers) was recovered in the southern Caribbean on the offshore Venezuelan Isla Blanquilla, more than $1900 \mathrm{~km}$ from its nearest sampled clade member in the Bahamas (Fig. 5a, Table 2).

Pronounced levels of Bahamas clade mitochondrial genetic variation (Table 3 ) resolved into three well-defined tip clades (Fig. 5b). One tip clade had a distinct geographic signature, being exclusive to the geographically isolated Cape Verde population (Figs. 5a-c). The other two tip clades coexisted throughout the Florida Keys, Bahamas, and Bermuda populations (Figs. 5a-c, Table 2). Unlike the case for other Caribbean nominal $B$. exustus taxa, these latter populations showed no significant genetic subdivision, remarkably so in the case of the Bermudan population, where only $0.01 \%$ of variation could be attributed to its isolation by more than $1500 \mathrm{~km}$ of open ocean (Table 4). In concordance with the AMOVA results, relatively high levels of gene flow were detected by ML estimation among the Florida Keys, Bahamas, and Bermuda populations (Table 5).

One of the more enigmatic results of the earlier study (Lee and Ó Foighil 2004) concerned a rare nominal B. exustus Key Biscayne clade, sister to the Bahamas clade, represented by three subadult specimens sampled in a marginal Brachidontes habitat in Key Biscayne, southern Florida. Our expanded regional sampling (Fig. 5a) showed that this clade was widespread in the Antilles, being exclusively present in samples from Cuba, Jamaica, Puerto Rico, Barbados, and one location in Trinidad. Therefore, we now refer to it as the "Antilles clade." The majority of samples collected from Venezuela also belonged to this clade (Table 2).

The Antilles clade contained a well-defined phylogenetic mitochondrial dichotomy, dated by the COI calibrations at 2.1-2.9 million years ago (Fig. 5b), but not reciprocated when cross-referenced with the nuclear markers (Fig. 3). The two mitochondrial tip clades were unequally represented, both numerically and spatially, across the Antilles clade's range. One (A) was predominant in all sampling sites and a much rarer tip clade (B) was present only in the two southernmost sites, Trinidad and Venezuela (Table 2). Although tip clade A contained a few common widely distributed haplotypes (Fig. 5d), its constituent populations were significantly subdivided (Table 4). Interestingly, haplotype diversity was higher in southern populations (Barbados, Trinidad, Venezuela) than in the Greater Antilles populations, and southern haplotypes were often several mutational steps away from the centrally positioned haplotypes in the network, whereas most of the Greater Antilles haplotypes were just one step away (Fig. 5d). A bidirectional but asymmetric gene flow pattern among most populations was indicated by ML estimation, and levels were especially high among the Greater Antilles locations (Table 5).

\section{Gulf and Atlantic clades}

The previous Floridian study (Lee and Ó Foighil 2004) recovered a Gulf/Atlantic genetic disjunction in which reciprocally monophyletic sister groups, the Gulf and Atlantic clades, were found on the respective flanks of the Floridian 
CARIBBEAN MUSSEL PHYLOGEOGRAPHY

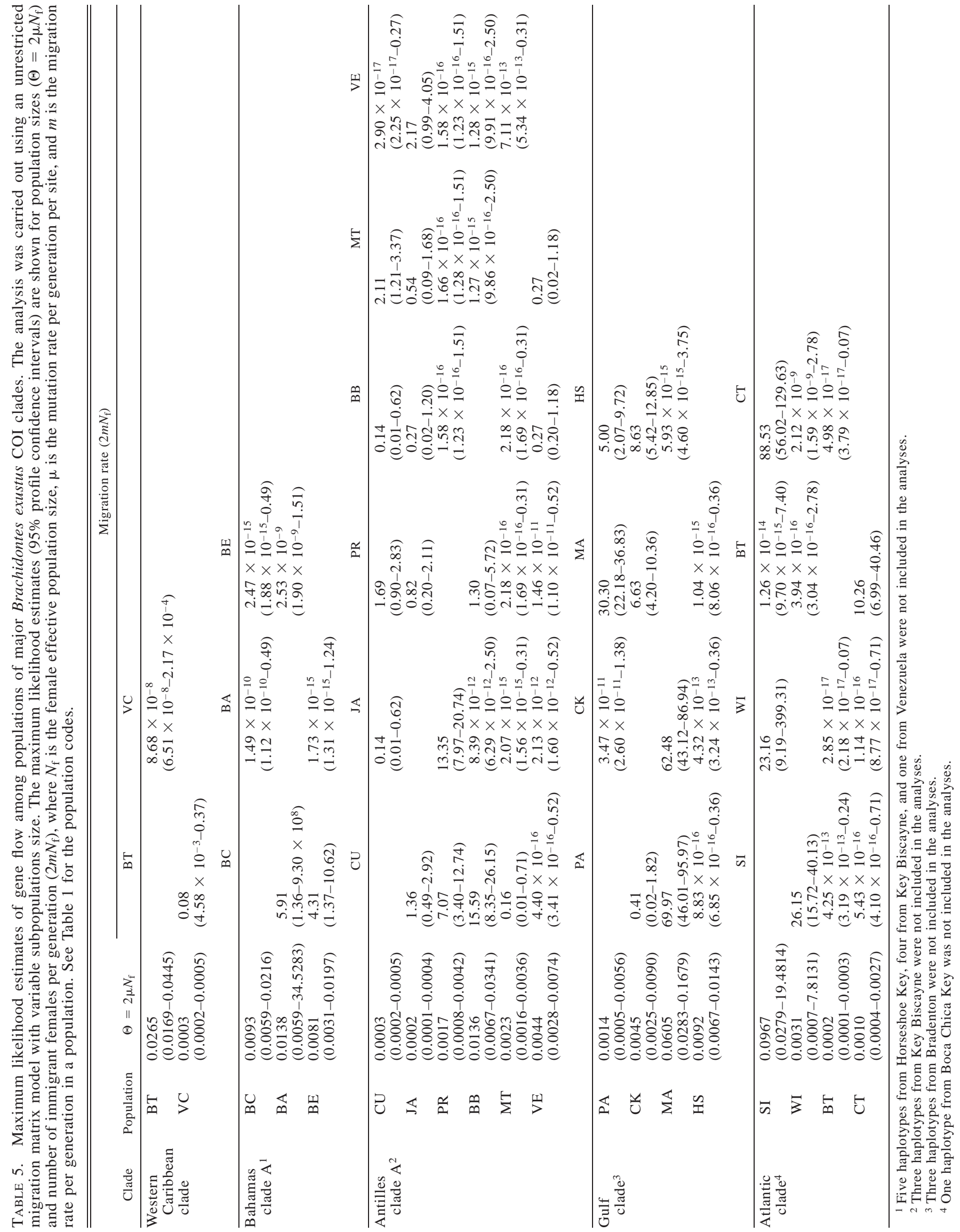



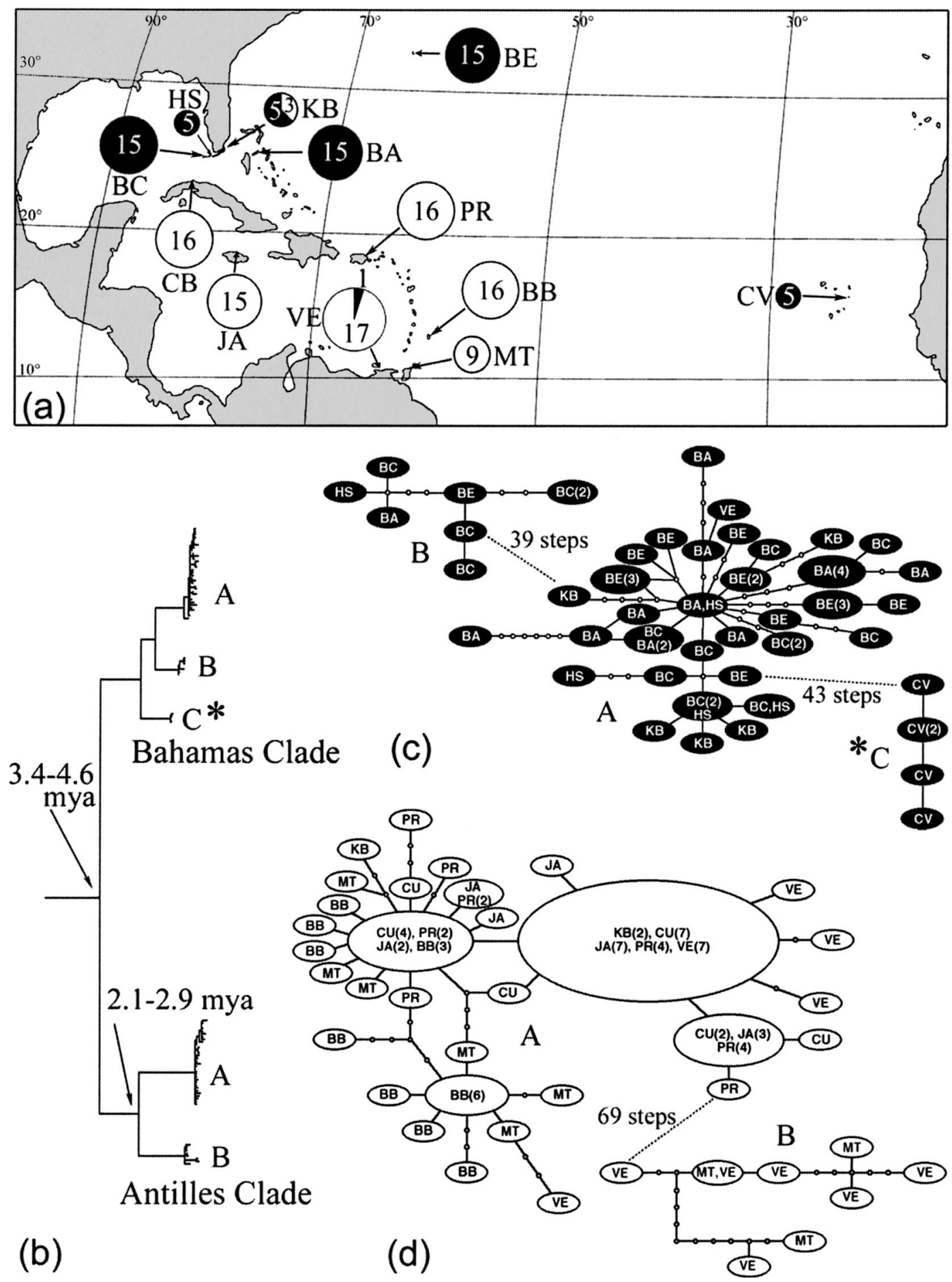

FIG. 5. Brachidontes exustus Bahamas and Antilles sister clades. (a) Map showing sampling locations (black circles, Bahamas clade; white, Antilles clade; see Table 1 for locality code); (b) portion of COI Bayesian tree showing sister group relationships and their inferred divergence times; and (c) statistical parsimony networks of the Bahamas clade and (d) of the Antilles clade. COI tip clades are labeled in capital letters in the Bayesian tree (b) and in the parsimony networks (c, d). In the parsimony network, the observed COI haplotypes are represented by ovals sized according to their relative abundance (numbers $>1$ given in parentheses) and labeled and color-coded to reflect sampling location. Smaller unlabeled circles represent inferred missing haplotypes and genotypes for B. puniceus from Cape Verde are marked by asterisks. Branch lengths connecting tip clades are from a minimum spanning tree computed using Arlequin 2.001 (Schneider et al. 2000). 

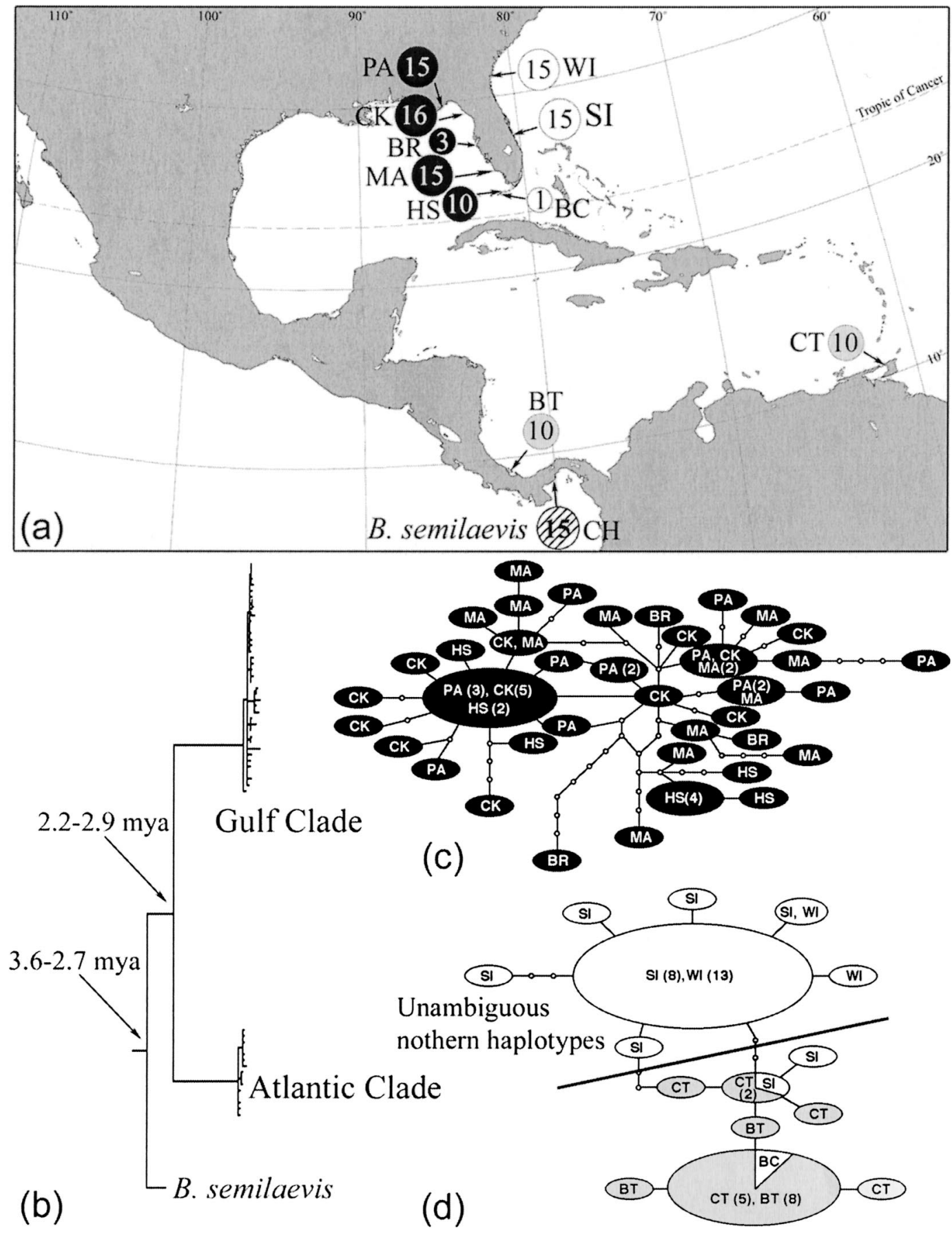

FIG. 6. Brachidontes exustus Gulf and Atlantic sister clades. (a) Map showing sampling locations (black circles, Gulf clade; white, Atlantic clade northern samples; gray, Atlantic southern samples; see Table 1 for locality code); (b) portion of COI Bayesian tree showing sister group relationships and their inferred divergence times; and (c) statistical parsimony networks of the Gulf clade and (d) of the Atlantic clade (white indicates individuals collected from the northern sampling sites and gray for those from the southern sites). In the parsimony network, the observed COI haplotypes are represented by ovals sized according to their relative abundance (numbers $>1$ given in parentheses) and labeled and color-coded to reflect sampling location. Smaller unlabeled circles represent inferred missing haplotypes. Branch lengths connecting tip clades are from minimum spanning tree computed using Arlequin 2.001 (Schneider et al. 2000).

peninsula. A lineage specific mitochondrial COI calibration, based on the split of these sister lineages with their putative transisthmian geminate species B. semilaevis (Fig. 3), dated the Gulf/Atlantic disjunction to 2.2-2.9 million years ago (Fig. 6b).
Extending the sampling effort throughout the Caribbean Basin did not reveal any additional members of the Gulf clade. However, Atlantic clade populations (confirmed for both mitochondrial and nuclear markers) were recovered from two sites in the southern Caribbean: Bocas del Toro, 
TABLE 6. Estimated ancestral population parameters, $\Theta(=2 N \mu$ for the mtDNA genome, where $N$ is the effective population size and $\mu$ is the mutation rate per generation) and $g$ (the exponential growth rate of the population), for the Atlantic clade (all haplotypes) and for the unambiguous northern haplotypes $( \pm \mathrm{SD})$. Estimates are based on 10 replicate analyses of COI third-codon positions. The times at which the effective population size was $1 \%$ of its current size were calculated based on $g$ and $\mu$ (mutation rates per generation calibrated for a cession of transisthmian gene flow at 3.6 million years [Coates et al. 1992] and at 2.7 million years [Marshall 1988]). The $95 \%$ confidence intervals are presented after each estimate.

\begin{tabular}{lccc}
\hline \hline \multicolumn{1}{c}{ Atlantic clade } & $\Theta$ & $g$ & Time to $1 \%$ relative $N$ \\
\hline All haplotypes & $0.064 \pm 0.055$ & $639.8 \pm 471.4$ & $88,554(60,793-162,981)$ \\
& & $118,073(81,057-217,307)$ & $8738(7571-10,332)$ \\
Unambiguous northern haplotypes only & $1.564 \pm 2.287$ & $6483.6 \pm 1613.7$ & $11,651(10,094-13,776)$ \\
& & & \\
& & &
\end{tabular}

Panama (where they coexisted with western Caribbean clade members on mangrove roots), and Chaguaramas, Trinidad (Fig. 6a, Table 2). Both of these new locations are more than $1600 \mathrm{~km}$ south of the previous southernmost sampling record, a solitary individual present in an otherwise exclusively Bahamas clade Florida Keys sample (Boca Chica Key; Fig. 6a).

Figure $6 \mathrm{~d}$ shows an unrooted gene network incorporating all Atlantic clade mitochondrial genotypes. Its relatively truncated topology reflected the fact that the Atlantic clade had the lowest nucleotide $(H)$ and haplotype $(\pi)$ diversities of all the five nominal B. exustus taxa (Table 3). Regional subdivisions were clearly evident among northern (white) and southern (gray) populations: the network had two distinct topological domains, separated by three inferred mutational steps, and each domain was dominated numerically by mussels sampled in one regional population. However, although AMOVA analyses indicated that $76.96 \%$ of the Atlantic clade variation was due to the north-south subdivision, this value was not statistically significant (Table 4), and a surprisingly high rate of Trinidad-to-Florida gene flow was obtained by ML estimation (Table 5). These indicators of north-south genetic connectivity stem from the placement of three northern individuals within the predominantly southern topolog- ical domain, two of which (including the sole Florida Keys, $\mathrm{BC}$, specimen) shared the same COI genotypes with southern mussels (Fig. 6d).

In the earlier study of Floridian B. exustus diversity, relative estimates of $N$ through time for the Atlantic clade were consistent with its local persistence through the last ice age maximum (Lee and Ó Foighil 2004). Incorporation of the new southern genotypes allows us to recalculate ancestral demographic structure for both the entire clade and for a parsed Floridian dataset containing only those haplotypes forming an unambiguously northern genealogy (Fig. 6d). Table 6 shows the parameters $\Theta$ and $g$, calculated for the total Atlantic clade (all haplotypes) and for the unambiguously northern clade, using Fluctuate (Kuhner et al. 1998), and the time to $1 \% N$ (relative to present-day estimates), for the two clock calibrations. Plots of the relative estimates of $N$ through time are presented in Figure 7. When haplotypes from southern sampling sites and the three northern haplotypes nested in the southern group were excluded from the dataset, the estimated growth rate $(g)$ for the truncated northern dataset was an order of magnitude larger than the rate calculated for all Atlantic clade haplotypes (Table 6), suggesting accelerated population growth in the former. The range of estimated

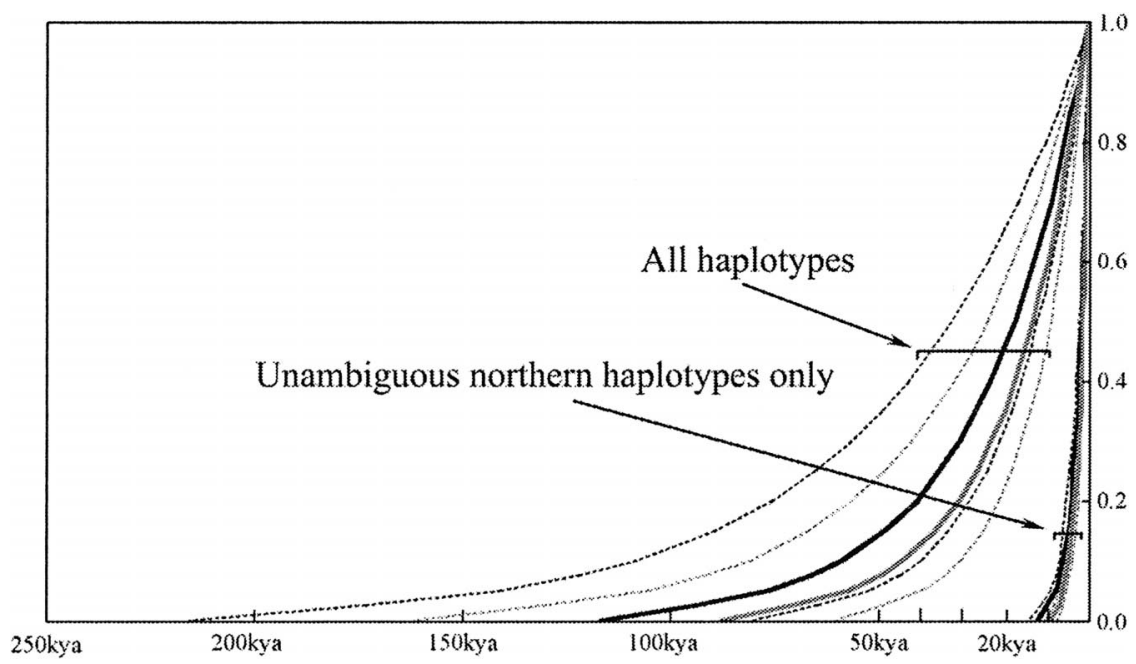

FIG. 7. Patterns of growth for the Brachidontes exustus Atlantic clade, calculated separately for all COI haplotypes recovered and also for a parsed subset of haplotypes comprising an unambiguously northern genealogy (Fig. 6d), based on estimates of the parameter $g$ (exponential growth rate of the population) generated jointly with $\Theta(=2 N \mu$ for the mtDNA genome, where $N$ is the effective population size and $\mu$ is the mutation rate per generation) using Fluctuate (Kuhner et al. 1998). The X-axis represents time (thousands of years) and the $y$-axis represents the ancestral effective population sizes relative to current size. Two growth trajectories (with 95\% confidence intervals: dashed lines) are based on Brachidontes-specific COI third-codon mutation rates per generation, calibrated for a cessation of gene flow at 3.6 million years ago (Coates et al. 1992; black lines) and at 2.7 million years ago (Marshall 1988; gray lines). 
ages (including $95 \%$ confidence intervals) by which $N$ drops to $1 \%$ of its present-day size was from 60,000 to 217,000 years ago for the entire Atlantic clade and from 7000 to 14,000 years ago for the unambiguously northern group. This latter estimate postdates the end of the last glacial maximum (Williams et al. 1998) and is considerably more recent than the earlier figure of 52,000 to 120,000 years ago based on all northern haplotypes (Lee and Ó Foighil 2004).

\section{DISCUSSION}

We were interested in establishing how the Gulf-Atlantic genetic disjunction for the Caribbean B. exustus species complex scaled relative to the phylogenetic structuring experienced over the rest of its collective geographic range. Our results show it to be merely one of multiple latent regional genetic disjunctions involving five sibling species that appear to be the product of a long history of regional cladogenesis. We were unable to reliably distinguish these five cryptic taxa on morphological grounds only and relied on a conservative phylogenetic diagnosis, using the criterion of reciprocal monophyly for both nuclear and mitochondrial markers. Gene tree topologies and lineage-specific molecular clock calibrations reveal that the generative cladogenetic events were temporally and spatially heterogeneous. Disjunctions involving the three stem lineages clearly predate formation of the Isthmus of Panama and the Caribbean Sea (Fig. 3). However, of the five Caribbean cryptic species, only the western Caribbean clade has a transisthmian sister taxon and may therefore be putatively a direct vicariant product of American Seaway closure. The remaining four Caribbean taxa have within-basin sister relationships although molecular clock estimations place the Bahamas/Antilles disjunction at/before closure of the Isthmus (3.4-4.6 million years ago) and the Gulf/Atlantic split postclosure (2.2-2.9 million years ago).

\section{New Insights into the Scorched Mussel Gulf/Atlantic Disjunction}

Our earlier study (Lee and Ó Foighil 2004), based on Floridian and Bahamian scorched mussel samples, concluded that the Gulf/Atlantic genetic disjunction for this morphospecies represented a case of temporal pseudocongruence (Cunningham and Collins 1994). In other words, although it also appeared to be a product of Floridian vicariance, the Pliocene cladogenic event underlying the scorched mussel disjunction was considerably older than the Pleistocene genetic disjunctions of many coexisting taxa (Avise 2000). Our new data allow placement of the scorched mussel Gulf/Atlantic disjunction into a comprehensive regional phylogenetic context and seriously undermine the hypothesis of a Floridian vicariant genesis, implying that the pseudocongruence may be both biogeographic and temporal in nature.

The unexpected discovery of Atlantic clade populations in the southern Caribbean opens up the possibility that the Gulf/ Atlantic split may not have originated within the temperate Carolinian zoogeographic zone. The unrooted mitochondrial COI network (Fig. 6d) indicates that a minority of northern haplotypes was newly introduced from southern source populations. Northward Atlantic clade trans-basin migration may be an ongoing process because a high rate of directional gene flow was estimated from Trinidad to Florida (Table 5). However, the large bulk of the northern haplotypes form an exclusively northern subclade and the network topology (Fig. $6 d$ ) is equivocal concerning its potential source/founder evolutionary relationship with its predominantly southern sister subclade. Nevertheless, several lines of indirect evidence indicate that the northern subclade may represent a founder population in a relatively marginal environment. Mussels from southern sites grow much larger than northern samples-most Panamian specimens collected in this study were more than twice the shell length of the largest specimen recovered from northern populations $(25 \mathrm{~mm})$. The latter represent the highest-latitude populations (Florida to North Carolina) found in this morphospecies (Abbott 1974), and this detail is pertinent because there was a significant southward displacement of nearshore North American Atlantic coast faunas during the last ice age maximum (Cronin 1988; Pielou 1991; Wares 2002). It is therefore interesting to note that the range of estimated ages in which $N$ for the exclusively northern subclade drops to $1 \%$ of its present-day size was from 7000 to 14,000 years ago (including $95 \%$ confidence intervals; Fig. 7, Table 4). This time frame is well short of the end of the last glacial maximum 20,000 years ago (Williams et al. 1998), indicating that the B. exustus Atlantic clade may have established its current Florida-North Carolina distribution much later than its divergence from the sister Gulf clade (2.18-2.91 million years ago).

As with any molecular clock-based estimation, our calculations of ancestral population size through time for the Atlantic northern subclade contain a number of sources of potential error; for example, biogeographic-based mutation rate calibrations tend to give inflated estimates relative to fossil record calibrations (T. M. Collins 1996; Hillis et al. 1996; Marko 2002). If the onset of mitochondrial COI genetic divergence among ancestral B. semilaevis and Gulf/Atlantic clade geminate lineages occurred significantly before closure of the Isthmus of Panama, our lineage-specific mutation rate calibrations would be overestimates (Knowlton and Weigt 1998; Marko 2002) and the ancestral population size values underestimates. Such a scenario is entirely possible, given that the fossil record indicates a Middle Miocene onset of uplift-associated marine faunal change (L. S. Collins 1996; Vermeij 2001) and that our lineage-specific rates are unusually high (Lee and Ó Foighil 2004). It should be kept in mind, however, that mytilid mitochondrial genomes exhibit high rates of mutation relative to other marine invertebrates (Wares and Cunningham 2001). Fortunately, the inference of a recent rapid decline in ancestral effective population size in the Atlantic northern subclade is robust to a wide range of molecular clock calibrations. For instance, a recent study of reef-dwelling arcid bivalve transisthmian geminate species pairs, which used fossil-calibrated mitochondrial COI divergences, found that one of the most divergent pairs may be more than 30 million years old (Marko 2002). We consider it unlikely that transisthmian divergences for Brachidontes geminates are in this age bracket: Knowlton and Weigt (1998) found that the best (most recently diverged) transisthmian taxa for such estimates are mangrove associates and our putative Brachidontes geminates are common in this habitat. Nevertheless, even if a calibration of 30 million years is 
applied, slowing the inferred mutation rate by an order of magnitude, the estimated Atlantic northern subclade effective population size still plunges to about $35 \%$ of its current size by 20,000 years, a value consistent with a hypothesis of local extirpation and subsequent postglacial recolonization (Marko 2004).

It is also possible that our ancestral demography calculations through time for the Atlantic northern subclade are overestimates due to an undersampling of southern Caribbean populations. Our two southern sampling sites, in Panama and Trinidad, where Atlantic clade individuals were recovered are more than $2200 \mathrm{~km}$ apart and we managed to obtain and genotype a mere 20 Atlantic clade individuals over this extensive geographic range. It would not be surprising if some of the exclusively northern haplotypes (Fig. 6d) were also eventually found to be present in southern populations, a result that would act to erode the network of exclusively northern genotypes and accelerate the inferred rate of northern population decrease through time.

Based on the available mitochondrial COI data, we consider it likely that the Atlantic clade northern populations stem from multiple, temporally heterogeneous, post-ice age maximum colonization events by southern tropical Caribbean source populations. A minority of these colonizations appear to have been recent; however most northern COI genotypes stem from an inferred earlier wave of colonization that we date to 7000-14,000 years ago (Fig. 7, Table 6). The generality of this surprising pattern of trans-Caribbean scorched mussel Gulf/Atlantic Floridian pseudocongruence is not clear at present, but it may well be a recurring biogeographic theme among some members of the large fraction of Carolinian morphospecies that share the scorched mussel's nominal distribution range from North Carolina to the southern Caribbean (Abbott 1974).

\section{Allopatric Speciation Drives Scorched Mussel Cladogenesis}

Our results increase the number of Caribbean Brachidontes species from two to six and are consistent with numerous molecular studies of invertebrate species complexes that have prompted significantly amplified estimates of marine biodiversity (Knowlton 2000; Thorpe et al. 2000). Viewed regionally, only B. modiolus approximated the common Caribbean condition of extensive within-basin distribution associated with little apparent genetic structuring (Mitton et al. 1989; Lacson 1992; Hateley and Sleeter 1993; Shulman and Bermingham 1995; Lessios et al. 2001, 2003; Rocha et al. 2002; Williams and Reid 2004). In contrast, the five cryptic $B$. exustus species had an intriguing pattern of within-basin distribution characterized by distinct geographic areas of ecological dominance, often adjoining those of sister taxa, and, in general, our individual sampling locations were dominated by a particular species. Only two of 21 sampling sites contained large numbers of more than one coexisting cryptic species and in both cases the coexisting taxa were not sister species: western Caribbean clade + Atlantic clade in Bocas del Toro, Panama, mangrove habitat and Gulf clade $+\mathrm{Ba}-$ hamas clade in Horseshoe site, Florida Keys (Table 2). This pattern of distribution is consistent with allopatric speciation origins for all five cryptic taxa, coupled with restricted post- speciation range extensions (Meyer 2003; Williams and Reid 2004). Allopatric speciation is a common mode of marine diversification, even in species with extended pelagic larval development (Colborn et al. 2001; Lessios et al. 2001; Meyer 2003; Williams and Reid 2004) and may result from either vicariant division or from founder dispersal (Paulay and Meyer 2002). With the exception of the western Caribbean clade, which appears to be the product of transisthmian vicariance (Figs. 3, 4), and the incipient founder differentiation of the Cape Verdean, Bahamas, clade population (Fig. 5), it is not possible to distinguish among these two allopatric mechanisms for the remainder of the study taxa.

\section{Maintenance of Allopatry}

One of the most salient questions in the ecology and evolution of nearshore tropical marine faunas concerns the degree of connectivity among geographically discrete populations (Warner and Palumbi 2003). Do they primarily represent closed systems with very little population exchange, even on relatively modest geographic scales (Cowen et al. 2000)? Or might they be best described as open systems (Mora and Sale 2002)? Evidence can be found for a spectrum of connectivity, from extensive (in the absence of biogeographic barriers) for species with broad larval dispersal potential (Lessios et al. 2001; Rocha et al. 2002) to almost nonexistent in many nominal taxa with reduced pelagic larval development (Kirkendale and Meyer 2004; Meyer et al. 2005). Of particular interest are taxa, such as the scorched mussel species complex, in which pronounced latent genetic structuring persists despite extended pelagic larval development (Barber et al. 2002; Taylor and Hellberg 2003a; Williams and Reid 2004). With the exception of the cleaner goby, Elacatinus (Taylor and Hellberg 2003a), this pattern has not previously been documented in the Caribbean fauna, in the absence of distinct habitat partitioning (Rocha et al. 2005). The sampling focus of the Elacatinus study loosely approximated that of the Bahamas and Antilles mussel sister clades (Fig. 5). The primary genetic disjunctions recovered in comparable samples of both studies were congruent in that they distinguished northern Bahamian from Antillean lineages, although mitochondrial genetic divergence levels were much less in the goby than in the mussels (Taylor and Hellberg 2003a).

Although the most prominent instances of scorched mussel genetic structuring involved that of the cryptic species themselves (Figs. 4-6), four of the five cryptic species also showed significant genetic differentiation of their constituent populations (Table 4), implying that local recruitment dynamics predominate. The exception is the Bahamas clade in that it lacked significant genetic differentiation among its western Atlantic/Caribbean populations, despite their incorporation of two divergent mitochondrial clades and an isolated oceanic island population on Bermuda (Fig. 5, Table 4). The Bermudan shallow water marine fauna represents a moderately impoverished oceanic extension of the Caribbean fauna (Sterrer 1986,1998 ) and the nearest source populations are approximately $1500 \mathrm{~km}$ to the southwest in southern Florida and the Bahamas. Based on net transport of drift bottles, this distance represents a minimum passage of 21-30 days for 
passive pelagic transport of larvae (Jackson 1986) and our results indicate that an oceanic dispersal filter of this geographic/temporal scale is well within the larval dispersal capabilities of scorched mussels. Nevertheless, the lack of Bermudan genetic distinctiveness is surprising, given that populations of the sister Antillean clade exhibit significant genetic substructure (Table 4), despite being separated by a series of much smaller individual dispersal filters, and that Pleistocene fossil Brachidontes have been found on Bermuda (Richards et al. 1969). There is some evidence for a partial turnover of the Bermudan marine malacofauna on ecological time scales (Abbott and Jensen 1967; Sterrer 1986). We hypothesize that the Bermudan scorched mussel population may have a history of intermittent persistence and that the presentday population may be much younger than the fossil record would indicate.

The Elacatinus Caribbean data has been the subject of contrasting genes versus oceanography interpretations (Colin 2003; Taylor and Hellberg 2003b; Warner and Palumbi 2003). We cannot distinguish among these possibilities directly for scorched mussel lineages or rule out a role for undocumented human-mediated introductions. However, several lines of indirect evidence favor the hypothesis that the predominantly allopatric distributions are maintained over evolutionary time scales, primarily by postrecruitment ecological factors rather than by oceanographic barriers to larval-mediated gene flow. For instance, data supporting evolutionary recent trans-basin gene flow among the geographically disjunct Atlantic clade northern and southern populations (Fig. 6d, Tables 5) undermines the case that oceanographic barriers to larval dispersal explains the apparent absence of this clade in central Caribbean insular habitats (Fig. 6a). In addition, the geographic scale of the Bahamas/ Antilles sister taxon disjunction (145 km between Cuba and the Florida Keys), which may have persisted for the past 3.44.6 million years, was dwarfed by within-clade scales of more evolutionarily recent realized gene flow: the Bahamas clade range expansion across the Atlantic (Figs. 5a-c) and the basin-spanning distribution of the most common Antilles clade haplotype (Fig. 5d). Perhaps the most compelling evidence is that cryptic scorched mussel species were not restricted to their core distributional areas and were encountered (coexisting in low frequency with the local dominant) in other parts of the Basin, for example, three subadult Antilles clade individuals in Key Biscayne (Fig. 5, Table 2), one Bahamas clade individual in Venezuela (Fig. 5, Table 2), and one Atlantic clade southern genotype in the Boca Chica Florida Key (Fig. 6, Table 2). These individuals were typed for both nuclear and mitochondrial markers and appear to represent genuine allorecruits rather than mere introgressed mitochondrial genomes. The Key Biscayne Antillean clade subadults are particularly interesting because, in our earlier study of Floridian/Bahamian scorched mussel populations (Lee and Ó Foighil 2004), we failed to recover any Antilles clade adults - a result consistent with allorecruitment of these three individuals from a geographically distinct source population, such as Cuba (Fig. 5). Subadult specimens were genotyped in the Key Biscayne sample simply due to the very low numbers of scorched mussels ( $N=8$; Table 2) encountered in this apparently marginal location (Lee and Ó Foighil 2004) and the resulting need to process every individual retrieved. Given these observations, a genes not oceanography (Taylor and Hellberg 2003b; Warner and Palumbi 2003) hypothesis for the maintenance of scorched mussel allopatry predicts that careful genotyping of subadult recruits in southern Florida would reveal that Antilles clade member have a widespread, low-frequency presence in southern Floridian juvenile scorched mussel cohorts. In summary, although local autorecruitment dynamics appear to routinely predominate for most of the five cryptic taxa (Table 4), our data collectively imply that postrecruitment environmental exclusion processes have played, and are playing, a key role in the long-term maintenance of within-basin scorched mussel allopatry.

At present, we can only speculate as to the nature of the environmental exclusion mechanism(s), although there seems to be a good fit with continental and oceanic nearshore tropical distribution pattern expectations (Abbott 1960; Vermeij 1987; Williams and Reid 2004; Meyer et al. 2005). The western Caribbean (Fig. 4a) and Gulf and Atlantic clades (Fig. 6a) were almost exclusively found in relatively high-nutrient, lower-salinity continental habitats, whereas the Bahamas and Antilles sister taxa appeared to be restricted to more oceanic, higher-salinity, and lower-productivity conditions, typically on offshore islands (Fig. 5a). This putative environmental effect can be observed over small geographic distances in the Florida Keys, where there are marked habitat and faunal distinctions among the more continental inner (bayside) and the more oceanic outer (oceanside) habitats (Mikkelsen and Bieler 2000; Bieler and Mikkelsen 2004). We sampled two adjacent sites in the lower Keys, a Bahamas clade-dominated oceanside location (Boca Chica Key) that lacked Gulf clade specimens, and a bayside location (Horseshoe, West Summerland Key) in which the majority of individuals typed belonged to the Gulf clade and Bahamas clade specimens were in the minority (Table 2).

The Bahamas and Antilles sister clades inhabit ostensibly similar and adjacent island habitats in their respective northern and central/southern Caribbean core ranges (Fig. 5a). Paradoxically, there are no obvious environmental factors that could plausibly operate as differential postrecruitment exclusion mechanisms and these two intertidal suspension-feeding cryptic mussel species are unlikely to differ significantly in trophic modes. Our data are consistent with the hypothesis that this narrow geographic disjunction (145 km from Cuba to the Florida Keys) may have persisted since their presumed allopatric speciation 3.4-4.6 million years ago. One speculative possibility is that latent coevolved biotic interactions, which also developed in allopatry, may operate to critically reduce the survivorship/reproduction of allorecruits. The possible nature of such putative coevolved biotic interactions remains obscure, but this hypothesis may be testable using caged and uncaged reciprocal transplant experiments.

Clade-specific environmental exclusion mechanisms also likely played a decisive role in determining which of the five regional cryptic scorched mussel species colonized the newly available Atlantic coast (Florida to North Carolina) habitat following the northward expansion of nearshore temperate faunas at the end of the last ice age (Cronin 1988; Pielou 1991; Wares 2002). Although our results show that the At- 
lantic clade northern populations stem from multiple, temporally heterogeneous colonization events, starting at 700014,000 years ago by a southern Caribbean clade (Figs. 6, 7), they do not indicate why only this clade was successful in becoming established. A simple, pelagic larval-mediated dispersal model would predict that the actual source lineage in the southern Caribbean represented the least likely colonizer among the five candidate cryptic species, especially so relative to the Gulf, Bahamas, and Antilles clades. This is because its relatively remote southern Caribbean location (i.e., the newly available habitat) would inevitably lead to disproportionately severe dilution/mortality for its larvae as they dispersed across the Caribbean Basin, yielding much lower representation in Atlantic coast scorched mussel colonizing larval cohorts (Cowen et al. 2000) compared to the more geographically proximate Gulf, Bahamas, and Antilles clades. As discussed above, continental environmental conditions may have prevented Atlantic coast establishment of the Bahamas/Antilles sister clades. However, the apparent failure of the geographically proximate continental Gulf clade to colonize the Atlantic flank of Florida, thereby leaving it open for long-distance colonization by a sister tropical southern Caribbean species, is quite enigmatic, but hints at a narrower window of ecological specialization in the former. It would seem that not all scorched mussels are created equally.

\section{ACKNOWLEDGMENTS}

We are grateful to the following colleagues for providing generous sampling assistance: R. Bieler, G. Bigatti, R. Bullock, K. Coates, R. Cipriani, E. Coan, R. Collin, T. Collins, L. Davis, A. Fields, H. Fortunata, C. Franz, A. Gutiérres, M. Hellberg, D. Herbert, I. Kappner, C. Lam, C. Leigh, T. Leigh, P. Mikkelsen, T. Nangammbi, E. Rolán, T. J. Smith, R. Walker, R. Willan, and K. Whelan. The manuscript was improved by the constructive input of two anonymous reviewers. J. Megahan kindly drew the shell outlines used in Figure 3, and J.-K. Park generated initial sequences for this project. Supported by National Science Foundation award OCE-0099084 to DÓF.

\section{Literature Cited}

Abbott, R. T. 1960. The genus Strombus in the Indo-Pacific. IndoPac. Mollusca 1:33-146.

__ 1974. American seashells. Van Nostrand Reinhold, New York.

Abbott, R. T., and R. H. Jensen. 1967. Molluscan faunal changes around Bermuda. Science 155:687-688.

Avise, J. C. 1992. Molecular population structure and the biogeographic history of a regional fauna: a case history with lessons for conservation biology. Oikos 63:62-76.

- 2000. Phylogeography: the history and formation of species. Harvard Univ. Press, Cambridge, MA.

Avise, J. C., C. A. Reeb, and N. C. Saunders. 1987. Geographic population structure and species differences in mitochondrial DNA of mouthbrooding marine catfishes (Ariidae) and demersal spawning toadfishes (Battrachoididae). Evolution 41:991-1002.

Barber, P. H., S. R. Palumbi, M. V. Erdmann, and M. K. Moosa. 2002. Sharp genetic breaks among populations of Haptosquilla pulchella (Stomatopoda) indicate limits to larval transport: patterns, causes and consequences. Mol. Ecol. 11:659-674.

Beerli, P., and J. Felsenstein. 2001. Maximum likelihood estimation of a migration matrix and effective population sizes in $n$ sub- populations by using a coalescent approach. Proc. Natl. Acad. Sci. USA 98:4563-4568.

Bert, T. M. 1986. Speciation in western Atlantic stone crabs (genus Menippe): the role of geological processes and climatic events in the formation and distribution of species. Mar. Biol. 93: $157-170$.

Bert, T. M., and W. S. Arnold. 1995. An empirical test of predictions of two competing models for the maintenance and fate of hybrid zones: both models are supported in a hard-clam hybrid zone. Evolution 49:276-289.

Bert, T. M., and R. G. Harrison. 1988. Hybridization in western Atlantic stone crabs (genus Menippe): evolutionary history and ecological context influence species interactions. Evolution 42: 528-544.

Bieler, R., and P. M. Mikkelsen. 2004. Marine bivalves of the Florida Keys: a qualitative faunal analysis based on original collections, museum holdings and literature data. Malacologia 46:503-544.

Borsa, P., M. Naciri, L. Bahiri, L. Chikhi, F. J. García de León, G. Kotoulas, and F. Bonhomme. 1997. Infraspecific zoogeography of the Mediterranean: population genetic analysis on sixteen Atlanto-Mediterranean species (fishes and invertebrates). Vie Milieu 47:295-305.

Briggs, J. C. 1970. A faunal history of the North Atlantic Ocean. Syst. Zool. 19:19-34.

- 1974 . Marine zoogeography. McGraw Hill, New York.

Campos, B., and L. Ramorino. 1980. Larval and early benthic stages of Brachidontes granulata (Bivalvia: Mytilidae). Veliger 22: 277-281.

Chase, M. R., R. J. Etter, M. A. Rex, and J. M. Quattro. 1998. Bathymetric patterns of genetic variation in a deep-sea protobranch bivalve, Demninucula atacellana. Mar. Biol. 131: 301-308.

Clement, M., D. Posada, and K. A. Crandall. 2000. TCS: a computer program to estimate gene genealogies. Mol. Ecol. 9:1657-1660.

Coan, E. V., P. V. Scott, and F. R. Bernard. 2000. Bivalve seashells of North America. Santa Barbara Museum of Natural History, Santa Barbara, CA.

Coates, A. G., J. B. C. Jackson, L. S. Collins, T. M. Cronin, H. J. Dowsett, L. M. Bybell, P. Jung, and J. A. Obando. 1992. Closure of the Isthmus of Panama: the near-shore marine record of Costa Rica and western Panama. Geol. Soc. Am. Bull. 104:814-828.

Colborn, J., R. E. Crabtree, J. B. Shaklee, E. Pfeiler, and B. W. Bowen. 2001. The evolutionary enigma of bonefishes (Albula spp.): cryptic species and ancient separations in a globally distributed shorefish. Evolution 55:807-820.

Colin, P. L. 2003. Larvae retention: Genes or oceanography? Science 300:1657-1659.

Collin, R. 2001. The effects of mode of development on phylogeography and population structure of North Atlantic Crepidula (Gastropoda: Calyptraeidae). Mol. Ecol. 10:2249-2262.

_ 2002. Another last word on Crepidula convexa with a description of $C$. ustulatulina n. sp. (Gastropoda: Calyptraeidae) from the Gulf of Mexico and southern Florida. Bull. Mar. Sci. 70:177-184.

Collins, L. S. 1996. Environmental changes in Caribbean shallow waters relative to the closing tropical American seaway. Pp. 130167 in J. B. Jackson, A. F. Budd, and A. G. Coates, eds. Evolution and environment in tropical America. Univ. of Chicago Press, Chicago.

Collins, T. M. 1996. Molecular comparisons of transisthmian species pairs: rates and patterns of evolution. Pp. 303-330 in J. B. Jackson, A. F. Budd, and A. G. Coates, eds. Evolution and environment in tropical America. Univ. of Chicago Press, Chicago.

Cowen, R. K., K. M. M. Lwiza, S. Sponaugle, C. B. Paris, and D. B. Olson. 2000. Connectivity of marine populations: Open or closed? Science 287:857-859.

Cronin, T. M. 1988. Evolution of marine climates of the US Atlantic coast during the past four million years. Philos. Trans. R. Soc. B. 318:661-678.

Cunningham, C. W., and T. M. Collins. 1994. Developing model systems for molecular biogeography: vicariance and interchange in marine invertebrates. Pp. 405-433 in B. Schierwater, B. Streit, 
G. P. Wagner, and R. DeSalle, eds. Molecular ecology and evolution: approaches and applications. Birkhauser Verlag, Basel, Switzerland.

- 1998 . Beyond area relationships: extinction and reclonization in molecular marine biogeography. Pp. 279-321 in R. DeSalle and B. Schierwater, eds. Molecular approaches to ecology and evolution. Birkhauser Verlag, Basel, Switzerland.

Cunningham, C. W., L. W. Buss, and C. W. Anderson. 1991. Molecular and geological evidence of shared history between hermit crabs and the symbiotic genus Hydractinia. Evolution 458: 1301-1316.

Distel, D. L. 2000. Phylogenetic relationships among Mytilidae (Bivalvia): 18S rRNA data suggest convergence in mytilid body plans. Mol. Phylogenet. Evol. 15:25-33.

Droxler, A. W., K. Burke, A. D. Cunningham, A. C. Hine, E. Rosencrantx, D. Duncan, P. Hallock, and E. Robinson. 1998. Caribbean constraints on circulation between Atlantic and Pacific Oceans over the past 40 million years. Pp. 160-191 in T. Crowley and K. Burke, eds. Tectonic boundary conditions for climate reconstruction. Oxford Univ. Press, Oxford, U.K.

Duggins, C. F., A. A. Karlin, T. A. Mousseau, and K. G. Relyea. 1995. Analysis of a hybrid zone in Fundulus majalis in a northeastern Florida ecotone. Heredity 74:117-128.

Edwards, S., and P. Beerli. 2000. Gene divergence, population divergence, and the variance in coalescence time in phylogeographic studies. Evolution 54:1839-1854.

Excoffier, L., P. E. Smouse, and J. M. Quattro. 1992. Analysis of molecular variance inferred from metric distances among DNA haplotypes: application to human mitochondrial DNA restriction data. Genetics 131:45479-45491.

Farris, J. S., M. Källersjö, A. G. Kluge, and C. Bult. 1995. Testing significance of congruence. Cladistics 10:315-319.

Felder, D. L., and J. L. Staton. 1994. Genetic differentiation in the Gulf-Atlantic species complexes of Sesarma and Uca (Crustacea: Decapoda: Brachyura). J. Crustacean Biol. 14:191-209.

Felsenstein, J. 1981. Evolutionary trees from DNA sequences: a maximum likelihood approach. J. Mol. Evol. 32:79-81.

- 1985. Confidence limits on phylogenies: an approach using the bootstrap. Evolution 39:783-791.

Fields, A., and E. Moore. 1983. The larval biology of Brachidontes modiolus (Linné, 1767) Bivalvia: Mytilidae). Veliger 26:52-61.

Folmer, O., M. Black, W. Hoeh, R. Lutz, and R. Vrijenhork. 1994. DNA primers for amplification of mitochondrial cytochrome $c$ oxidase subunit I from diverse metazoan invertebrates. Mol. Mar. Biol. Biotechnol. 3:294-299.

Gold, J. R., and L. R. Richardson. 1998. Mitochondrial DNA diversification and population structure in fishes from the Gulf of Mexico and western Atlantic. J. Hered. 89:404-414.

Gopurenko, D., J. M. Hughes, and C. P. Keenan. 1999. Mitochondrial DNA evidence for rapid colonization of the Indo-West Pacific by the mudcrab Scylla serrata. Mar. Biol. 134:227-233.

Grosberg, R., and C. W. Cunningham. 2001. Genetic structure in the sea from populations to communities. Pp. 61-84 in M. D. Bertness, S. D. Gaines, and M. E. Hay, eds. Marine community ecology. Sinauer Associates, Sunderland, MA.

Hare, M. P., and J. C. Avise. 1996. Molecular genetic analysis of a stepped multilocus cline in the American oyster (Crassostrea virginica). Evolution 50:2305-2315.

__ 1998. Population structure in the American oyster as inferred by nuclear gene genealogies. Mol. Biol. Evol. 15: 119-128.

Hare, M. P., S. A. Karl, and J. C. Avise. 1996. Anonymous nuclear DNA markers in the American oyster and their implications for the heterozygote deficiency phenonemon in marine bivalves. Mol. Biol. Evol. 13:334-345.

Hateley, J. G., and T. D. Sleeter. 1993. A biochemical genetic investigation of spiny lobster (Panulirus argus) stock replenishment in Bermuda. Bull. Mar. Sci. 52:993-1006.

Hillis, D. M., B. K. Mable, and C. Moritz. 1996. Applications of molecular systematics. Pp. 515-530 in D. M. Hillis, C. Moritz, and B. K. Mable, eds. Molecular systematics. 2nd ed. Sinauer Associates, Sunderland, MA.

Iturralde-Vinent, M. A., and R. D. E. MacPhee. 1999. Paleogeog- raphy of the Caribbean region: implications for Cenozoic biogeography. Bull. Am. Mus. Nat. Hist. 283:1-95.

Jackson, J. B. C. 1986. Modes of dispersal of clonal benthic invertebrates: consequences for species' distributions and genetic structure of local populations. Bull. Mar. Sci. 39:588-606.

Karl, S. A., and J. C. Avise. 1992. Balancing selection at allozyme loci in oysters: implications from nuclear RFLPs. Science 256: $100-102$.

Kirkendale, L. A., and C. P. Meyer. 2004. Phylogeography of the Patelloida profunda group (Gastropoda: Lottidae): diversification in a dispersal-driven marine system. Mol. Ecol. 13: 2749-2762.

Kirkendale, L. A., T. Lee, P. Baker, and D. Ó Foighil. 2004. Oysters of the Conch Republic (Florida Keys): a molecular phylogenetic study of Parahyotissa mcgintyi, Teskeyostrea weberi and Ostreola equestris. Malacologia 46:309-326.

Knowlton, N. 2000. Molecular genetic analyses of species boundaries in the sea. Hydrobiologia 420:73-90.

Knowlton, N., and L. A. Weigt. 1998. New dates and new rates for divergence across the Isthmus of Panama. Proc. R. Soc. Lond. B 265:2257-2263.

Kuhner, M. K., J. Yamato, and J. Felsenstein. 1998. Maximum likelihood estimation of population growth rates based on the coalescent. Genetics 149:429-434.

Lacson, J. M. 1992. Minimal genetic variation among samples of six species of coral reef fishes collected at La Parguera, Puerto Rico, and Discovery Bay, Jamaica. Mar. Biol. 112:327-331.

Lavery, S., C. Moritz, and D. R. Fielder. 1996. Genetic patterns suggest exponential population growth in a declining species. Mol. Biol. Evol. 13:1106-1113.

Lee, T., and D. Ó Foighil. 2004. Hidden Floridian biodiversity: mitochondrial and nuclear gene trees reveal four cryptic species within the scorched mussel, Brachidontes exustus, species complex. Mol. Ecol. 13:3527-3542.

Lessios, H. A., B. D. Kessing, and J. S. Pearse. 2001. Phylogeography of the pantropical sea urchin Eucidaris in relation to land barriers and ocean currents. Evolution 53:955-975.

Lessios, H. A., J. Kane, and D. R. Robertson. 2003. Phylogeography of the pantropical sea urchin Tripneustes: contrasting patterns of population structure between oceans. Evolution 57: 2026-2036.

Marko, P. B. 2002. Fossil calibration of molecular clocks and the divergence times of geminate species pairs separated by the Isthmus of Panama. Mol. Biol. Evol. 19:2005-2021.

_ _ 2004. 'WWhat's larvae got to do with it?' Disparate patterns of post-glacial population structure in two benthic marine gastropods with identical dispersal potential. Mol. Ecol. 13: 597-611.

Marshall, L. G. 1988. Land mammals and the Great American Interchange. Am. Sci. 76:380-388.

McDonald, J. H., B. C. Verrelli, and L. B. Geyer. 1996. Lack of geographic variation in anonymous nuclear polymorphisms in the American oyster, Crassostrea virginica. Mol. Biol. Evol. 13: $1114-1118$.

Meyer, C. P. 2003. Molecular systematics of cowries (Gastropoda: Cypraeidae) and diversification patterns in the tropics. Biol. J. Linn. Soc. 79:401-459.

Meyer, C. P., J. B. Geller, and G. Paulay. 2005. Fine scale endemism on coral reefs: archipelagic differentiation in turbinid gastropods. Evolution 59:113-125.

Mikkelsen, P. M., and R. Bieler. 2000. Marine bivalves of the Florida Keys: discovered biodiversity. Pp. 367-387 in E. M. Harper, J. D. Taylor, and J. A. Crame, eds. The evolutionary biology of the Bivalvia. Geological Society of London, Special Publication no. 177

Mitton, J. B., C. J. Berg Jr., and K. S. Orr. 1989. Population structure, larval dispersal, and gene flow in the queen conch, Strombus gigas, of the Caribbean. Biol. Bull. 177:356-362.

Mora, C., and P. F. Sale. 2002. Are populations of coral reef fish open or closed? Trends Ecol. Evol. 17:422-428.

Morton, B. 1988. The population dynamics and reproductive cycle of Brachidontes variabilis (Bivalvia: Mytilidae) in a Hong Kong mangrove. Malacol. Rev. 21:109-117. 
Nei, M. 1987. Molecular evolutionary genetics. Columbia Univ. Press, New York.

Nei, M., and W.-H. Li. 1979. Mathematical model for studying genetic variation in terms of restriction endonuclease. Proc. Natl. Acad. Sci. USA 76:5269-5273.

Ó Foighil, D., T. J. Hilbish, and R. M. Showman. 1996. Mitochondrial gene variation in Mercenaria clam sibling species reveals a relict secondary contact zone in the western Gulf of Mexico. Mar. Biol. 126:675-683.

Palumbi, S. R. 1994. Genetic divergence, reproductive isolation, and marine speciation. Annu. Rev. Ecol. Syst. 25:547-572. . 1996. Nucleic acids. II. The polymerase chain reaction. Pp. 205-247 in D. M. Hillis, C. Moritz, and B. K. Mable, eds. Molecular systematics. 2nd ed. Sinauer Associates, Sunderland, MA.

Park, J.-K., and D. Ó Foighil. 2000. Sphaeriid and corbiculid clams represent separate heterodont bivalve radiations into freshwater environments. Mol. Phylogenet. Evol. 14:75-88.

Paulay, G., and C. Meyer. 2002. Diversification in the tropical Pacific: comparisons between marine and terrestrial systems and the importance of founder speciation. Integr. Comp. Biol. 42: 922-934.

Pielou, E. C. 1991. After the ice age. Univ. of Chicago Press, Chicago.

Posada, D., and K. A. Crandall. 1998. MODELTEST: testing the model of DNA substitution. Bioinformatics 14:817-818.

Quesada, H., D. A. G. Skibinski, and D. O. F. Skibinski. 1996. Sexbiased heteroplasmy and mitochondrial DNA inheritance in the mussel Mytilus galloprovincialis Lmk. Curr. Genet. 29:423-426.

Randazzo, A. F., and D. S. Jones. 1997. The geology of Florida. Univ. Press of Florida, Gainesville.

Rawson, P. D., and T. J. Hilbish. 1995. Evolutionary relationships among the male and female mitochondrial DNA lineages in the Mytilus edulis species complex. Mol. Biol. Evol. 12:893-901.

Reeb, C. A., and J. C. Avise. 1990. A genetic discontinuity in a continuously distributed species: mitochondrial DNA in the American oyster, Crassostrea virginica. Genetics 124:397-406.

Richards, H. G., R. T. Abbott, and T. Skymer. 1969. The marine Pleistocene mollusks of Bermuda. Not. Nat. 425:1-10.

Rocha, L. A., A. L. Bass, D. R. Robertson, and B. W. Bowen. 2002. Adult habitat preferences, larval dispersal, and the comparative phylogeography of three Atlantic surgeonfishes (Teleostei: Acanthuridae). Mol. Ecol. 11:243-252.

Rocha, L. A., D. R. Robertson, J. Roman, and B. W. Bowen. 2005. Ecological speciation in tropical reef fishes. Proc. R. Soc. B 272: 573-579.

Ronquist, F., and J. P. Huelsenbeck. 2003. MrBayes 3: Bayesian phylogenetic inference under mixed models. Bioinformatics 19: 1572-1574.

Sarver, S. K., M. C. Landrum, and D. W. Foltz. 1992. Genetics and taxonomy of ribbed mussels (Geukensia spp.). Mar. Biol. 113: 385-390.

Saunders, N. C., L. G. Kessler, and J. C. Avise. 1986. Genetic variation and geographic differentiation in mitochondrial DNA of the horseshoe crab, Limulus polyphemus. Genetics 112: 613-627.

Schizas, N. V., G. T. Street, B. C. Coul, G. T. Chandler, and J. M. Quattro. 1999. Molecular population structure of the marine ben- thic copepod Microarthridion littorale along the southeastern and Gulf coasts of the USA. Mar. Biol. 135:399-405.

Schneider, S., D. Roessli, and L. Excoffier. 2000. Arlequin: a software for population genetics data analysis. Ver. 2.000. Genetics and Biometry Laboratory, University of Geneva, Switzerland.

Shulman, M. J., and E. Bermingham. 1995. Early life histories, ocean currents, and the population genetics of Caribbean reef fishes. Evolution 49:897-910.

Sterrer, W. 1986. Marine fauna and flora of Bermuda. Wiley and Sons, New York.

1998. How many species are there in Bermuda? Bull. Mar Sci. 62:809-840.

Swofford, D. L. 2003. PAUP*: phylogenetic analysis using parsimony (*and other methods). Ver. 4. Sinauer Associates, Sunderland, MA.

Tajima, F. 1983. Evolutioanry relationship of DNA sequences in finite populations. Genetics 105:437-460.

- 1989. Statistical method for testing the neutral mutation hypothesis by DNA polymorphism. Genetics 123:585-595.

Taylor, M. S., and M. E. Hellberg. 2003a. Genetic evidence for local retention of pelagic larvae in a Caribbean reef fish. Science 299:107-109.

2003b. Larvae retention: Genes or oceanography? Science 300:1657-1659.

Templeton, A. R., K. A. Crandall, and C. F. Sing. 1992. A cladistic analysis of phenotypic associations with haplotypes inferred from restriction endonuclease mapping and DNA sequence data. III. Cladogram estimation. Genetics 132:619-633.

Thompson, J. D., T. J. Gibson, F. Plewniak, F. Jeanmougin, and D. G. Higgins. 1997. The CLUSTAL X window interface: flexible strategies for multiple sequence alignment aided by quality analysis tools. Nucleic Acids Res. 25:4876-4882.

Thorpe, J. P., A. M. Sole-Cava, and P. C. Watts. 2000. Exploited marine invertebrates: genetics and fisheries. Hydrobiologia 420: $165-184$.

Vermeij, G. J. 1987. The dispersal barrier in the tropical Pacific: implications for molluscan speciation and extinction. Evolution 41:1046-1058

2001. Distribution, history, and taxonomy of the Thais clade (Gastropoda: Muricidae) in the Neogene of tropical America. J. Paleontol. 75:697-705.

Wares, J. P. 2002. Community genetics in the northwestern Atlantic intertidal. Mol. Ecol. 11:1131-1144.

Wares, J. P., and C. W. Cunningham. 2001. Phylogeography and historical ecology of the North Atlantic intertidal. Evolution 55: 2455-2469.

Warner, R. R., and S. R. Palumbi. 2003. Larvae retention: Genes or oceanography? Science 300:1657-1659.

Webb, S. D. 1990. Historical biogeography. Pp. 70-100 in R. I. Myers and J. J. Ewel, eds. Ecosystems of Florida. Univ. of Central Florida Press, Orlando.

White, L. R., B. A. McPherson, and J. R. Stauffer. 1996. Molecular genetic identification tools for the unionids of French Creek, Pennsylvania. Malacologia 38:181-202.

Williams, D., D. Dunkerley, P. DeDekker, P. Kershaw, and M. Chappel. 1998. Quaternary environments. Arnold, London.

Williams, S. T., and D. G. Reid. 2004. Speciation and diversity on tropical rocky shores: a global phylogeny of snails of the genus Echinolittorina. Evolution 58:2227-2251.

Corresponding Editor: D. McHugh 